\title{
Multiple Mycotoxins in Rice: Occurrence and Health Risk Assessment in Children and Adults of Punjab, Pakistan
}

\author{
Saima Majeed ${ }^{1,2}$, Marthe De Boevre ${ }^{3}{ }^{(D}$, Sarah De Saeger ${ }^{3}{ }^{(1)}$, Waqar Rauf ${ }^{1}$, Abdul Tawab ${ }^{1}$, \\ Fazal-e-Habib ${ }^{1}$, Moazur Rahman ${ }^{1}$ and Mazhar Iqbal ${ }^{1, *}$ \\ 1 Health Biotechnology Division, National Institute for Biotechnology and Genetic Engineering (NIBGE), \\ Faisalabad 38000, Pakistan; saima.nibge@gmail.com (S.M.); wadhamite@gmail.com (W.R.); \\ atawab1@yahoo.com (A.T.); fazal_ehabib@yahoo.com (F.-e.-H.); moazur@yahoo.com (M.R.) \\ 2 Department of Biotechnology NIBGE, Pakistan Institute of Engineering and Applied Sciences, Nilore 45650, \\ Islamabad, Pakistan \\ 3 Laboratory of Food Analysis, Department of Bioanalysis, Faculty of Pharmaceutical Sciences, \\ Ghent University, Ghent 9000, Belgium; Marthe.DeBoevre@ugent.be (M.D.B.); \\ sarah.desaeger@ugent.be (S.D.S.) \\ * Correspondence: hamzamgondal@gmail.com; Tel.: +92-41-9201403
}

Received: 12 December 2017; Accepted: 7 February 2018; Published: 10 February 2018

\begin{abstract}
Mycotoxin contamination in rice can create a health risk for the consumers. In this study, the measurement of 23 mycotoxins in rice samples $(n=180)$ was performed using a validated LC-MS/MS method. A food frequency questionnaire was used to get rice consumption data for the assessment of mycotoxin dietary exposure, before calculating the health risk in adults and children of north and south regions of the Pakistani Punjab province. The prevalence of aflatoxin $B_{1}(56 \%)$, aflatoxin $\mathrm{B}_{2}(48 \%)$, nivalenol $(28 \%)$, diacetoxyscirpenol $(23 \%)$, fumonisin $\mathrm{B}_{1}(42 \%)$, zearalenone $(15 \%)$, HT- 2 toxin $(10 \%)$, deoxynivalenol $(8 \%)$, and ochratoxin A $(6 \%)$ was estimated in samples with a mean concentration range between 0.61 and $22.98 \mu \mathrm{g} / \mathrm{kg}$. Aflatoxin degradation by traditional Pakistani cooking recipes was evaluated and observed to be $41-63 \%$. The dietary exposure to aflatoxins exceeded the tolerable daily intake at all levels, and ochratoxin $\mathrm{A}$ and zearalenone posed health risk at high contamination and high consumption levels. The margin of aflatoxin $B_{1}$ exposure ranged between 10 and 69 in adults and 10 and 62 in children. The mean cancer risk by aflatoxin $B_{1}$ exposure was 0.070 (adults) and 0.071 (children) cases/year/100,000 people in South Punjab population, and 0.122 (adults) and 0.127 (children) cases/year/100,000 people in North Punjab population. This study will provide new insights for the planning and management of mycotoxins in Pakistan.
\end{abstract}

Keywords: LC-MS/MS; consumption; cooking effect; dietary exposure; aflatoxins; margin of exposure; cancer risk

Key Contribution: Mycotoxin contamination profile of Pakistani rice showed that the population is not exposed to a single mycotoxin but faces exposure to multiple mycotoxins. Moreover, there is a potential risk of developing aflatoxin-induced hepatocellular carcinoma (HCC) in Pakistan.

\section{Introduction}

Mycotoxins are naturally occurring toxic secondary metabolites produced by fungal species of the genera Aspergillus, Alternaria, Penicillium, Fusarium, Claviceps, and several others. Mycotoxins can be nephrotoxic, immunosuppressive, carcinogenic, and teratogenic. Trichothecenes, aflatoxins (AFs), Alternaria toxins, fumonisins (FBs), ochratoxin A (OTA), and zearalenone (ZEN) are the most important 
classes of mycotoxins causing a great variety of toxic effects in humans as well as in animals. Moreover, significant economic losses (25\%) occur in global agricultural commodities because of mycotoxin contamination [1].

Rice (Oryza sativa L.) is the most important source of human calorie intake and is a staple food in many countries [2]. Rice is one of the main crops of Pakistan with an annual production of 6800 metric ton dehulled rice and exports of about $60 \%$ of its annual production [3]. Rice, cultivated in flooded irrigation conditions and high moisture levels, is susceptible to get infected by mold and to subsequent mycotoxin contamination. Also inappropriate storage and climatic conditions such as floods and heavy rainfall at the time of harvest aggravate the situation. Sun-drying of rice, usually practiced by most of the farmers, is insufficient to reduce the moisture content, thus making rice more prone to fungal attack $[4,5]$.

The toxic effects caused by mycotoxins in animals and humans are called mycotoxicosis. The severity depends on many factors, especially the toxicity, mycotoxin contamination level, age and health status of the individual, along with possible synergistic effects of other chemicals encountered by the person [6]. The toxic effects range from acute (e.g., liver or kidney deterioration) to chronic (e.g., liver cancer); also mutagenic and teratogenic effects cause symptoms that range from skin irritation to immunosuppression, birth defects, neurotoxicity, and death [7]. More than $80 \%$ of hepatocellular carcinoma occur in low-income countries, having high risk factors of dietary aflatoxin exposure and chronic hepatitis $B$ and hepatitis $\mathrm{C}$ (HBV and HCV) viral infection [8]. According to the International Agency for Research on Cancer (IARC), aflatoxins are classified in Group 1 (carcinogenic to humans), whereas fumonisin $\mathrm{B}_{1}\left(\mathrm{FB}_{1}\right)$ is classified in Group $2 \mathrm{~B}$ (possibly carcinogenic to humans). Deoxynivalenol (DON) and other trichothecenes, as well as $\mathrm{AFB}_{1}$ can exert immunosuppressive effects, and $\mathrm{FB}_{1}$ may contribute to neural tube defects. Renal dysfunction due to OTA exposure is also a significant problem, especially because of the potential of the toxin to exacerbate impaired renal function in individuals with diabetes $[9,10]$.

To reduce the risk of mycotoxin consumption, legislative measures in different countries (e.g., EU, Japan, Korea, and China) have been setting the maximum permissible limits (ML) for different mycotoxins in food and feed. The European Commission has established the regulatory limits for mycotoxins in ready-to-use rice as follows: aflatoxin $\mathrm{B}_{1}(2 \mu \mathrm{g} / \mathrm{kg})$, total AFs $(4 \mu \mathrm{g} / \mathrm{kg}), \mathrm{OTA}(3 \mu \mathrm{g} / \mathrm{kg})$, DON $(750 \mu \mathrm{g} / \mathrm{kg}), \mathrm{ZEN}(75 \mu \mathrm{g} / \mathrm{kg})$, and an indicative value $(50 \mu \mathrm{g} / \mathrm{kg})$ for the sum of T-2 toxin (T2) and HT-2 toxin (HT2), while, for unprocessed rice, the established maximum limits are of $5 \mu \mathrm{g} / \mathrm{kg}$ for $\mathrm{AFB}_{1}, 10 \mu \mathrm{g} / \mathrm{kg}$ for the sum of aflatoxins (AFs), $5 \mu \mathrm{g} / \mathrm{kg}$ for OTA, $1250 \mu \mathrm{g} / \mathrm{kg}$ for DON, $100 \mu \mathrm{g} / \mathrm{kg}$ for ZEN, and $100 \mu \mathrm{g} / \mathrm{kg}$ for the sum of T2 and HT2 toxin [11,12].

Risk assessment is the combination of hazard identification and its characterization, exposure assessments, and subsequent risk characterization [13]. Many mycotoxins and toxigenic fungi have been identified as hazardous for health [14]. The characterization of hazards involve the measurement of the adverse health effects (both chronic and acute effects) caused by mycotoxins. For noncarcinogenic mycotoxins, a tolerable daily intake (TDI) or health-based guidance value (HBGV) has been established [15]. There is no acceptable daily intake (ADI) for aflatoxins as they are genotoxic and carcinogenic. If daily consumption is below the TDI values of mycotoxins, which is $1000 \mathrm{ng} / \mathrm{kg}$ body weight (b.w.) day for DON [16], $1200 \mathrm{ng} / \mathrm{kg}$ b.w. day for NIV [17], $100 \mathrm{ng} / \mathrm{kg}$ b.w. day for the sum of T-2 and HT-2 [18], $250 \mathrm{ng} / \mathrm{kg}$ b.w. day for ZEN [19], $2000 \mathrm{ng} / \mathrm{kg}$ b.w. day for FBs [20], and $17 \mathrm{ng} / \mathrm{kg}$ b.w. day for OTA [21], no adverse human health effects would appear over a life time.

Mycotoxin exposure assessment depends on the concentration of mycotoxins in food and on its intake. Risk characterization of nongenotoxic mycotoxins is done by comparing their exposure assessment with TDI. The risk characterization of genotoxic aflatoxins is usually executed by two approaches. The first one calculates cancer risk considering the prevalence of Hepatitis B Virus (HBV), on the basis of Hepatitis B surface antigen-postitive individuals ( $\mathrm{HBsAg}^{+}$individuals) in a given population and the cancer potency of aflatoxins in HBV carriers ( 0.3 cancers/year per 100,000 people per ng aflatoxin/kg b.w. day) and noncarriers (0.01 cancers/year per 100,000 people per ng 
aflatoxin/kg b.w. day) [22]. The second approach calculates the margin of exposure (MoE), which is the ratio between the toxicological threshold derived from animal studies and the estimated exposure in humans [23].

In Pakistan, the previous studies are mostly restricted to the determination of aflatoxins, zearalenone, and ochratoxin A contamination using nonconfirmatory analytical techniques [24-31], while mycotoxin contamination in rice at a global level has been reviewed by Ferre et al. and Tanaka et al. [32,33]. The studies on the dietary exposure to mycotoxins through rice consumption were performed in different countries, like Iran [34], United States [35], Turkey [36], Nigeria [37], France [38,39], Thailand [40], Korea [41], Vietnam [42,43], Mediterranean region [44], Africa [45], Spain [46], West Africa [47], and Portugal [48].

Limited data is available on the determination of and dietary exposure to multi-mycotoxins in Pakistani rice. Previous studies embarked upon the occurrence and dietary exposure to only a few mycotoxins (AFs, OTA, and ZEN) [25,26,30,31]. These studies did not include the dietary exposures to multiple mycotoxins, especially in children, are devoid of important parameters such as the calculation of the margin of exposure (MoE), and did not include a food frequency questionnaire (FFQ) and the degradation effect of Pakistani cooking recipes on the prevalent mycotoxins.

To the best of our knowledge, no study has been published on the simultaneous determination of multi-mycotoxins covering aflatoxins $\left(\mathrm{AFB}_{1}, \mathrm{AFB}_{2}, \mathrm{AFG}_{1}, \mathrm{AFG}_{2}\right), \mathrm{OTA}$, fumonisins $\left(\mathrm{FB}_{1}\right.$ and $\mathrm{FB}_{2}$ ), DON, nivalenol (NIV), diacetoxyscirpenol (DAS), HT2, and ZEN in Pakistani rice samples as well as on their dietary exposure in adults and children of Pakistan using confirmatory analytical techniques. Hence, to fill the aforementioned gaps, this work aimed to study the contamination levels of multi-mycotoxins in rice and their exposure risk assessment, based on rice consumption data in different regions. After accounting for the degradation effect of Pakistani cooking recipes on the prevalent mycotoxins, the study subsequently enabled us to determine the dietary exposure to mycotoxins in two population groups (adults and children), as the intake exceeding the provisional maximum tolerable daily intakes (PMTDIs) set by the European Food Safety Authority (EFSA) that poses health risks. Also, the potential risk of liver cancer arising from aflatoxin $\mathrm{B}_{1}$ intake was assessed in the Pakistani population of South Punjab (SP) and North Punjab (NP) regions. The study is likely to contribute to devising strategies for the planning and management of these food contaminants for the Pakistani Punjab population.

\section{Results}

\subsection{Validation}

The validation parameters were calculated from the relative peak area, using deepoxy-deoxynivalenol (DOM) as an internal standard for NIV, DON, fusarenon-X (FUS-X), neosolaniol (NEO), 3-acetyl-deoxynivalenol (3-ADON), 15-acetyl-deoxynivalenol (15-ADON), HT2, T2, and DAS, while zearalanone $(\mathrm{ZAN})$ was used for the rest of the analytes. The validation parameters were calculated in terms of linearity, limit of detection (LOD), limit of quantification (LOQ) (Table 1), \% apparent recovery, intraday repeatability, interday repeatability, and expanded measurement uncertainty (Table A1).

Table 1. Limits of detection (LOD) and limits of quantification (LOQ), linearity range, and coefficient of determination $\left(\mathrm{R}^{2}\right)$ of all the measured mycotoxins in rice.

\begin{tabular}{ccccc}
\hline Mycotoxin & LOD $(\mu \mathbf{g} / \mathbf{k g})$ & LOQ $(\mu \mathbf{g} / \mathbf{k g})$ & Range $(\mu \mathrm{g} / \mathbf{k g})$ & $\boldsymbol{R}^{\mathbf{2}}$ \\
\hline Zearalenone (ZEN) & 7 & 13 & $37.5-150$ & 0.998 \\
Enniatin B (ENNB) & 50 & 100 & $100-400$ & 0.992 \\
Roquefortine-C (ROQ-C) & 4 & 8 & $10-40$ & 0.993 \\
Sterigmatocystine (STREG) & 9 & 18 & $25-100$ & 0.995 \\
\hline
\end{tabular}


Table 1. Cont.

\begin{tabular}{|c|c|c|c|c|}
\hline Mycotoxin & LOD $(\mu \mathrm{g} / \mathrm{kg})$ & LOQ $(\mu \mathrm{g} / \mathrm{kg})$ & Range $(\mu \mathrm{g} / \mathrm{kg})$ & $R^{2}$ \\
\hline Alternariol methylether (AME) & 11 & 21 & $100-400$ & 0.991 \\
\hline Fumonisin $\mathrm{B}_{2}\left(\mathrm{FB}_{2}\right)$ & 17 & 35 & $100-400$ & 0.993 \\
\hline Ochratoxin A (OTA) & 0.75 & 2.5 & $2.5-20$ & 0.994 \\
\hline Fumonisin $\mathrm{B}_{3}\left(\mathrm{FB}_{3}\right)$ & 53 & 105 & $125-500$ & 0.995 \\
\hline $\mathrm{T}-2$ toxin (T2) & 22 & 44 & 50-200 & 0.993 \\
\hline Fumonisin $\mathrm{B}_{1}\left(\mathrm{FB}_{1}\right)$ & 13 & 26 & $100-400$ & 0.994 \\
\hline HT-2 toxin (HT2) & 13 & 26 & $50-200$ & 0.996 \\
\hline Alternariol $(\mathrm{AOH})$ & 22 & 44 & $50-200$ & 0.997 \\
\hline Diacetoxyscirpenol (DAS) & 3 & 6 & $10-40$ & 0.996 \\
\hline Aflatoxin $\mathrm{B}_{1}\left(\mathrm{AFB}_{1}\right)$ & 0.5 & 1.5 & $2.5-20$ & 0.994 \\
\hline Aflatoxin $\mathrm{B}_{2}\left(\mathrm{AFB}_{2}\right)$ & 0.5 & 1.5 & $2.5-20$ & 0.995 \\
\hline Aflatoxin $\mathrm{G}_{1}\left(\mathrm{AFG}_{1}\right)$ & 0.5 & 1.5 & $2.5-20$ & 0.996 \\
\hline Aflatoxin $\mathrm{G}_{2}\left(\mathrm{AFG}_{2}\right)$ & 0.5 & 1.5 & $2.5-20$ & 0.994 \\
\hline 15-Acetyl-deoxynivalenol (15-ADON) & 9 & 19 & $25-100$ & 0.995 \\
\hline 3-Acetyl-deoxynivalenol (3-ADON) & 16 & 33 & $50-200$ & 0.998 \\
\hline Fusarenon-X (FX) & 9 & 18 & $100-400$ & 0.993 \\
\hline Neosolaniol (NEO) & 12 & 23 & 50-200 & 0.996 \\
\hline Deoxynivalenol (DON) & 19 & 37 & $100-400$ & 0.992 \\
\hline Nivalenol (NIV) & 8 & 16 & $50-200$ & 0.999 \\
\hline
\end{tabular}

There were no interfering peaks at the retention times of all the analytes. The specificity was checked by running 20 blank rice samples on LC-MS/MS. The blank rice samples were spiked at five calibration levels with each compound, and the calibration curves were prepared each day in triplicate for four validation days. For the samples in which the contamination level did not fall in this validated range, either lower or higher range calibration curves were plotted to quantify them. The method-matched calibration curves fitted by linear regression showed a coefficient of determination $\left(\mathrm{R}^{2}\right)$ ranging from 0.991 to 0.999 . The mean recoveries for all the analytes were in the range of $80 \%$ to $111 \%$ (Table A1). The relative standard deviation was calculated in intraday repeatability $\left(\mathrm{RSD}_{\mathrm{r}}\right)$ and interday repeatability $\left(\mathrm{RSD}_{\mathrm{R}}\right)$ conditions and ranged from $3 \%$ to $14 \%$ and from $6 \%$ to $20 \%$, respectively. The LOD values of all the mycotoxins ranged from 0.5 to $53 \mu \mathrm{g} / \mathrm{kg}$. The LOQs for all the toxins ranged from 1.5 to $105 \mu \mathrm{g} / \mathrm{kg}$. The expanded measurement uncertainty ranged from $2.01 \%$ to $34.4 \%$. Method-matched calibration curves were used for the calculation of LOD and LOQ. The ion ratios of the qualifier and the quantifier ions were also monitored to successfully qualify the EU criteria to confirm the positive identification of a compound. The validation results of the current multi-mycotoxin method matched with the required European Commission Performance Criteria [49].

\subsection{Mycotoxin Levels}

The validated method was further used to investigate the incidence and content of mycotoxins in the collected rice samples. The results of the occurrence and levels of mycotoxins in rice samples are summarized in Table 2. Here, the mean is the average of mycotoxin contamination levels in all the samples including the negative samples, while considering their level as zero. The frequency of contamination of samples with $\mathrm{AFB}_{2}$ and $\mathrm{AFB}_{1}$ was $48 \%$ and $56 \%$, respectively, within the concentration range of $1.5-9.15 \mu \mathrm{g} / \mathrm{kg}$ and $1.5-40 \mu \mathrm{g} / \mathrm{kg}$, respectively. $\mathrm{AFG}_{1}$ and $\mathrm{AFG}_{2}$ were not detected in the tested samples. The results indicated that $\mathrm{FB}_{1}$ was found in $42 \%$ (level range from 26 to $75 \mu \mathrm{g} / \mathrm{kg}$ ) and ZEN in $15 \%$ (level range from 13 to $114 \mu \mathrm{g} / \mathrm{kg}$ ) of the collected samples. OTA was detected in $6 \%$ of the samples within a concentration range of $2.5-11 \mu \mathrm{g} / \mathrm{kg}$. Trichothecenes including DON, NIV, HT2, and DAS occurred in $8 \%, 28 \%, 10 \%$, and $23 \%$ samples, and the mean contamination level of these mycotoxins were $6.99,13.9,2.03$, and $1.60 \mu \mathrm{g} / \mathrm{kg}$, respectively. 
Table 2. Contamination levels $(\mu \mathrm{g} / \mathrm{kg}$ ) and incidence rate $(\%)$ of different mycotoxins in all rice samples $(n=180)$.

\begin{tabular}{ccccccccccc}
\hline $\begin{array}{c}\text { Descriptive } \\
\text { Statistics }\end{array}$ & AFB $_{\mathbf{2}}$ & AFB $_{\mathbf{1}}$ & AFs & NIV & DAS & FB $_{\mathbf{1}}$ & OTA & DON & HT2 & ZEN \\
\hline Mean & 1.91 & 5.84 & 7.75 & 13.8 & 1.60 & 22.9 & 0.610 & 6.99 & 2.03 & 8.48 \\
Median & $<$ LOD & 5.00 & 7.00 & $<$ LOD & $<$ LOD & $<$ LOD & $<$ LOD & $<$ LOD & $<$ LOD & $<$ LOD \\
Stdev. & 2.42 & 6.69 & 8.75 & 28.2 & 2.92 & 28.8 & 2.68 & 22.7 & 7.26 & 21.57 \\
Min. & $<$ LOD & $<$ LOD & $<$ LOD & $<$ LOD & $<$ LOD & $<$ LOD & $<$ LOD & $<$ LOD & $<$ LOD & $<$ LOD \\
Max. & 9.15 & 40.0 & 44.1 & 116 & 12.53 & 75.1 & 24.0 & 115 & 32.0 & 114 \\
P75 & 2.80 & 8.65 & 12.2 & 16.0 & 0.00 & 58.2 & $<$ LOD & $<$ LOD & $<$ LOD & $<$ LOD \\
P90 & 5.20 & 15.1 & 21.2 & 55.3 & 6.79 & 62.4 & $<$ LOD & $<$ LOD & $<$ LOD & 47.7 \\
P95 & 7.99 & 17.5 & 25.7 & 82.6 & 6.81 & 63.3 & 6.80 & 77.0 & 26.7 & 48.9 \\
P99 & 8.40 & 23.2 & 30.7 & 116 & 7.52 & 69.0 & 11.0 & 81.5 & 30.2 & 114 \\
\% freq. & 48 & 56 & 56 & 28 & 23 & 42 & 6.0 & 8.0 & 10 & 15 \\
\hline
\end{tabular}

Figure 1 shows the mean contamination levels in the positive samples only (above the LOQ). The incidence rate of the mycotoxins was higher in North Punjab than in South Punjab. The levels of contamination of mycotoxins in both regions were not significantly different $(p<0.05)$. Overall, $78 \%$ of the samples were contaminated with either one or more mycotoxins, while $57 \%$ of the samples were contaminated with more than one mycotoxins. In $40 \%$ of the samples, $\mathrm{AFB}_{1}$ and $\mathrm{AFB}_{2}$ co-occurred. In $21 \%$ of the samples, the co-occurrence of the mycotoxins produced from Fusarium and Aspergillus moulds was observed. The co-occurrence of these specific toxins can be taken into account in the design of future toxicity studies to examine their impact on animal and human health.

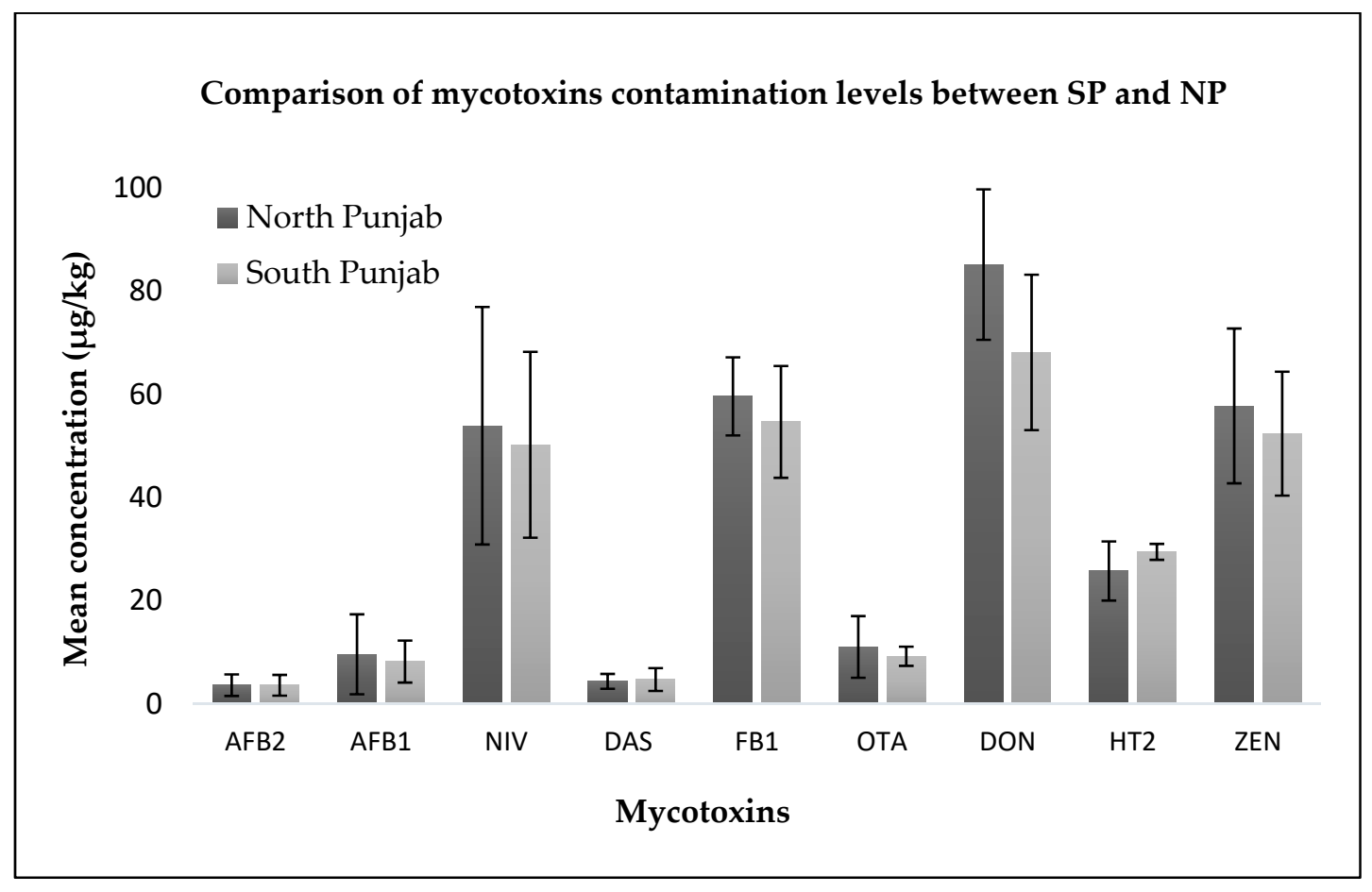

Figure 1. Comparison of the mean contamination levels of different mycotoxins in positive samples of the examined regions (NP: North Punjab; SP: South Punjab).

\subsection{Consumption of Rice}

On the basis of this survey, the mean rice consumption in the adult population (16-65 years) at national level was $108 \pm 24.1 \mathrm{~g}$ per individual on a daily basis, while the rice intake (g) per kg of body 
weight (b.w.) was $1.92 \pm 0.624 \mathrm{~g}$ (Table 3). Similarly, the mean rice consumption per capita and daily intake of rice per $\mathrm{kg}$ of body weight in children (7-15 years) at national level were estimated to be $56.65 \pm 15.3 \mathrm{~g} /$ individual/day and $1.97 \pm 0.619 \mathrm{~g} / \mathrm{kg}$ b.w. /day, respectively. The difference in rice consumption between adults and children of both regions was not significant $(p<0.05)$. In all the cases, the mean at national level was also not significantly different.

Table 3. Consumption data (mean $\pm \mathrm{SD}$ g/individual/day) and intake (mean $\pm \mathrm{SD} \mathrm{g} / \mathrm{kg}$ b.w. per day) of rice by children and adults in different regions of Pakistan and at national level (mean) obtained during the survey in 2015-2016.

\begin{tabular}{ccccc}
\hline \multirow{2}{*}{ Regions } & \multicolumn{2}{c}{ Adults } & \multicolumn{2}{c}{ Children } \\
\cline { 2 - 5 } & $\begin{array}{c}\text { Daily Intake (g) } \\
\text { Per Capita }\end{array}$ & $\begin{array}{c}\text { Daily Intake (g) } \\
\text { per kg Body } \\
\text { Weight }\end{array}$ & $\begin{array}{c}\text { Daily Intake (g) } \\
\text { per Capita }\end{array}$ & $\begin{array}{c}\text { Daily Intake (g) } \\
\text { per kg Body } \\
\text { Weight }\end{array}$ \\
\hline South Punjab & $91.3 \pm 24.1^{\mathrm{a}}$ & $1.66 \pm 0.508^{\mathrm{a}}$ & $50.8 \pm 11.8^{\mathrm{a}}$ & $1.68 \pm 0.513^{\mathrm{a}}$ \\
North Punjab & $124 \pm 24.0^{\mathrm{a}}$ & $2.18 \pm 0.739^{\mathrm{a}}$ & $62.5 \pm 18.8^{\mathrm{a}}$ & $2.26 \pm 0.726^{\mathrm{a}}$ \\
Mean (national level) & $108 \pm 24.1$ & $1.92 \pm 0.624$ & $56.6 \pm 15.3$ & $1.97 \pm 0.619$ \\
\hline
\end{tabular}

${ }^{\text {a }}$ Values with the same alphabet letters are not significantly different $(p<0.05)$.

\subsection{Effect of Cooking on $A F B_{1}$ and $A F B_{2}$ Levels}

During cooking, the first step involved washing that caused a $15 \%$ reduction of aflatoxins. The reduction in $\mathrm{AFB}_{1}(41-51 \%)$ and $\mathrm{AFB}_{2}(47-63 \%)$ in three cooking recipes of rice was measured (Table 4). Aflatoxin reduction was significantly higher $(p<0.05)$ in Biryani than in other cooking recipes. $\mathrm{AFB}_{1}$ reduction after cooking Pulao was in parallel with the reduction in boiled rice. The reduction level was different among these three cooking recipes because of differences in the cooking method. In boiled rice, the excess water was kept without adding any spices. In contrast, in Biryani recipe, the excess water was drained out after boiling the rice, spices (Coriander seed, cloves, cinnamon, ginger, black pepper, cardamom black, dry curry leaves, chili, and cumin seed) were added, and the rice was further cooked.

Table 4. Percentage of degradation of aflatoxin $B_{1}$ and $B_{2}$ in rice after washing and with different methods of cooking.

\begin{tabular}{|c|c|c|}
\hline Treatments & $\%$ Degradation $\mathrm{AFB}_{1}$ & $\%$ Degradation $\mathrm{AFB}_{2}$ \\
\hline Control & $0.0^{\mathrm{d}}$ & $0.0^{\mathrm{d}}$ \\
\hline Washing with water & $14 \pm 1.1^{\mathrm{c}}$ & $15 \pm 1.1^{\mathrm{c}}$ \\
\hline Pulao (Pakistani Recipe) & $41 \pm 1.2^{b}$ & $47 \pm 1.5^{b}$ \\
\hline Biryani (Pakistani Recipe) & $51 \pm 2.0^{\mathrm{a}}$ & $63 \pm 2.3^{a}$ \\
\hline Boiled rice & $42 \pm 1.4^{b}$ & $50 \pm 1.7^{b}$ \\
\hline On average & $45 \pm 1.4$ & $53 \pm 1.7$ \\
\hline
\end{tabular}

Values are the mean of three replicates. Values with different alphabet letters $\left({ }^{a}, b, c, d\right)$ indicate significant differences in percentage degradation in aflatoxin $B_{1}$ and aflatoxin $B_{2}$ among various cooking processes, as determined by Tukey's HSD test.

\subsection{Exposure Assessment of Mycotoxins in Pakistani Children and Adults}

The deterministic exposure levels associated with the mycotoxins $\mathrm{AFB}_{2}, \mathrm{AFB}_{1}, \mathrm{NIV}, \mathrm{DAS}$, $\mathrm{FB}_{1}$, OTA, DON, HT2 toxin, and ZEN are shown in Tables 5 and 6. The dietary exposure levels of $\mathrm{AFB}_{1}$ and $\mathrm{AFB}_{2}$ were taken after considering the mean reduction by cooking. We considered the two approaches, the mean concentration approach using fixed mycotoxin concentrations and variable values (mean, median, maximum, and percentiles) of consumption, and the second approach using a fixed consumption level with variable values (mean, median, maximum, and percentile) of 
mycotoxin level. In each approach, three scenarios, i.e., upper bound ( $<\mathrm{LOQ}=\mathrm{LOQ})$, medium bound $(<\mathrm{LOQ}=1 / 2 \mathrm{LOQ})$, and lower bound $(<\mathrm{LOQ}=0)$ were calculated, and the results of the medium bound are shown in Tables 5 and 6, while the results of the other two scenarios are given as supplementary material (Tables A2-A5).

In this study, the estimated $\mathrm{AFB}_{1}$ and $\mathrm{AFB}_{2}$ intake in Pakistani adults and children through rice consumption was above the safe limits at all calculated exposure levels. The exposure of OTA for both adults and children of SP and of NP exceeded the PMTDI of $17.1 \mathrm{ng} / \mathrm{kg}$ b.w./ day only at the maximum level [21]. There was no health risk associated with NIV exposure at the measured contamination levels as none of the exposure levels exceeded the safe health limits for NIV (1200 ng/kg b.w./day) [17].

All the determined exposure levels of HT2-toxin were found lower than the PMTDI value of $100 \mathrm{ng} / \mathrm{kg}$ b.w./day [18]. The exposure levels of DAS were compared with the TDI values of HT2 and T2 because of their structural similarity. All the estimated exposure levels of DAS, including the maximum exposure, were lower than the PMTDI value of HT2 and T2 (100 ng/kg b.w./day) [17]. However, the consumers' maximum exposure level for ZEN in NP showed a risk, as the values were higher than the TDI value (250 ng/kg b.w. day) [19].

Finally, when the two groups of subjects (adults and children) were compared, the children were found to be a vulnerable group for most contaminants, as the exposure was expressed in terms of per $\mathrm{kg}$ of body weight. The study reports, for the first time, the multiple-mycotoxins prevalence in Pakistani rice in combination with a consumption pattern of rice throughout Punjab, Pakistan, and the degradation of aflatoxins by the local cooking methods. This study also provides the first insight on the exposure to multiple mycotoxins associated with rice intake in Pakistan. The exposure of rice consumers in Pakistan (adults and children) to aflatoxins is above the toxicological reference values of AFs at all consumption levels. A combined intake of different mycotoxins at different concentration levels may lead to a higher risk than their single intake [50]. Nonetheless, we can conclude that the dietary exposures associated with the consumption of rice are considered a risk for public health. Hence, management strategies need to focus more on the reduction of mycotoxin contamination. 
Table 5. Deterministic dietary exposures (ng/kg b.w./day) through the consumption of rice contaminated by multiple mycotoxins by the adult group of the population in North and South Punjab of Pakistan, using the medium bound scenario ( $<\mathrm{LOQ}=1 / 2 \mathrm{LOQ}$ ). The calculations are based on (A) fixed mean mycotoxin concentration and variable rice consumption in the two regions and (B) fixed mean rice consumption and variable mycotoxins concentration in the two regions. Values exceeding the PMTDI (provisional maximum tolerable daily intake) are shown in bold.

\begin{tabular}{|c|c|c|c|c|c|c|c|c|c|c|c|c|c|c|c|c|c|c|}
\hline \multirow{3}{*}{$\begin{array}{l}\text { Descriptive } \\
\text { Statistics }\end{array}$} & \multicolumn{16}{|c|}{ (A) Deterministic Exposure Analysis at Fixed Mycotoxin Concentration and Variable Rice Consumption. } & & \\
\hline & \multicolumn{2}{|c|}{$\mathrm{AFB}_{2}$} & \multicolumn{2}{|c|}{$\mathrm{AFB}_{1}$} & \multicolumn{2}{|c|}{ NIV } & \multicolumn{2}{|c|}{ DAS } & \multicolumn{2}{|c|}{$\mathbf{F B}_{1}$} & \multicolumn{2}{|c|}{ OTA } & \multicolumn{2}{|c|}{ DON } & \multicolumn{2}{|c|}{ HT2 } & \multicolumn{2}{|c|}{ ZEN } \\
\hline & SP & NP & SP & NP & SP & NP & SP & NP & SP & NP & SP & NP & SP & NP & SP & NP & SP & NP \\
\hline Mean & 1.08 & 1.76 & 4.11 & 7.21 & 21.9 & 39.0 & 3.15 & 4.50 & 32.5 & 60.7 & 0.92 & 1.68 & 10.8 & 16.6 & 5.29 & 9.50 & 15.4 & 23.9 \\
\hline Median & 1.02 & 1.65 & 3.89 & 6.75 & 20.7 & 36.5 & 2.98 & 4.21 & 30.7 & 56.8 & 0.87 & 1.57 & 10.2 & 15.5 & 5.01 & 8.89 & 14.5 & 22.3 \\
\hline Min. & 0.660 & 0.871 & 2.50 & 3.54 & 13.3 & 19.2 & 1.92 & 2.21 & 19.7 & 29.8 & 0.56 & 0.82 & 6.58 & 8.15 & 3.22 & 4.67 & 9.34 & 11.7 \\
\hline P75 & 1.21 & 2.02 & 4.61 & 8.27 & 24.6 & 44.7 & 3.54 & 5.15 & 36.5 & 69.5 & 1.03 & 1.92 & 12.2 & 19.0 & 5.94 & 10.9 & 17.3 & 27.3 \\
\hline P90 & 1.62 & 2.95 & 6.18 & 12.1 & 32.9 & 65.2 & 4.74 & 7.52 & 48.8 & 101 & 1.38 & 2.81 & 16.3 & 27.8 & 7.96 & 15.9 & 23.1 & 39.8 \\
\hline P95 & 1.75 & 3.02 & 6.65 & 12.4 & 35.4 & 66.9 & 5.10 & 7.71 & 52.5 & 104 & 1.49 & 2.88 & 17.5 & 28.5 & 8.56 & 16.3 & 24.8 & 40.9 \\
\hline Max. & 2.48 & 4.15 & 9.44 & 17.0 & 50.2 & 91.9 & 7.24 & 10.6 & 74.6 & 143 & 2.12 & 3.96 & 24.8 & 39.1 & 12.2 & 22.4 & 35.3 & 56.3 \\
\hline \multicolumn{19}{|c|}{ (B) Deterministic Exposure Analysis at Fixed Rice Consumption and Variable Mycotoxin Concentration. } \\
\hline \multirow{2}{*}{$\begin{array}{l}\text { Descriptive } \\
\text { Statistics }\end{array}$} & \multicolumn{2}{|c|}{$\mathrm{AFB}_{2}$} & \multicolumn{2}{|c|}{$\mathrm{AFB}_{1}$} & \multicolumn{2}{|c|}{ NIV } & \multicolumn{2}{|c|}{ DAS } & \multicolumn{2}{|c|}{$\mathbf{F B}_{1}$} & \multicolumn{2}{|c|}{ OTA } & \multicolumn{2}{|c|}{ DON } & \multicolumn{2}{|c|}{ HT2 } & \multicolumn{2}{|c|}{ ZEN } \\
\hline & SP & NP & SP & NP & SP & NP & SP & NP & SP & NP & SP & NP & SP & NP & SP & NP & SP & NP \\
\hline Mean & 1.08 & 1.76 & 4.11 & 7.21 & 21.9 & 39.0 & 3.15 & 4.50 & 32.5 & 60.6 & 0.920 & 1.68 & 10.8 & 16.6 & 5.29 & 9.50 & 15.4 & 23.9 \\
\hline Median & 0.310 & 1.61 & 4.07 & 5.40 & $<\mathrm{LOD}$ & $<\mathrm{LOD}$ & $<\mathrm{LOD}$ & $<\mathrm{LOD}$ & $<\mathrm{LOD}$ & 14.2 & $<\mathrm{LOD}$ & $<\mathrm{LOD}$ & $<$ LOD & $<\mathrm{LOD}$ & $<\mathrm{LOD}$ & $<\mathrm{LOD}$ & $<\mathrm{LOD}$ & $<\mathrm{LOD}$ \\
\hline Min. & $<\mathrm{LOD}$ & $<\mathrm{LOD}$ & $<\mathrm{LOD}$ & $<\mathrm{LOD}$ & $<\mathrm{LOD}$ & $<\mathrm{LOD}$ & $<\mathrm{LOD}$ & $<\mathrm{LOD}$ & $<\mathrm{LOD}$ & $<\mathrm{LOD}$ & $<\mathrm{LOD}$ & $<\mathrm{LOD}$ & $<\mathrm{LOD}$ & $<\mathrm{LOD}$ & $<\mathrm{LOD}$ & $<\mathrm{LOD}$ & $<\mathrm{LOD}$ & $<\mathrm{LOD}$ \\
\hline P75 & 1.71 & 2.91 & 5.86 & 10.4 & 13.3 & 39.3 & 4.98 & 8.24 & 97.0 & 127 & $<\mathrm{LOD}$ & $<\mathrm{LOD}$ & $<\mathrm{LOD}$ & $<\mathrm{LOD}$ & $<\mathrm{LOD}$ & $<\mathrm{LOD}$ & 11.6 & 15.3 \\
\hline P90 & 2.66 & 4.38 & 10.9 & 16.3 & 90.2 & 133.8 & 11.3 & 14.8 & 97.0 & 139 & 1.24 & 1.64 & $<$ LOD & $<\mathrm{LOD}$ & 21.6 & 32.3 & 78.3 & 104 \\
\hline P95 & 4.39 & 6.69 & 13.3 & 19.0 & 124 & 192 & 11.3 & 14.9 & 104 & 144 & 4.88 & 15.1 & 124 & 168 & 21.6 & 58.68 & 79.5 & 111 \\
\hline Max. & 5.16 & 7.39 & 14.6 & 42.8 & 177 & 254. & 20.8 & 16.4 & 105 & 164 & 18.3 & 52.4 & 127 & 251 & 51.4 & 69.83 & 190 & 251 \\
\hline
\end{tabular}

PMTDI values (ng/kg b.w. day): $\mathrm{AFB}_{1}=0.0001, \mathrm{AFB}_{2}=0.0001, \mathrm{NIV}=700, \mathrm{DAS}=100, \mathrm{FB}_{1}=2000, \mathrm{OTA}=17, \mathrm{DON}=1000, \mathrm{HT} 2=100, \mathrm{ZEN}=250$. 
Table 6. Deterministic dietary exposures (ng/kg b.w./day) through the consumption of rice contaminated by multiple mycotoxins by children in North and South Punjab of Pakistan, using the medium bound scenario ( $<\mathrm{LOQ}=1 / 2 \mathrm{LOQ})$. The calculations are based on (A) fixed mean mycotoxin concentration and variable rice consumption in the two regions and (B) fixed mean rice consumption and variable mycotoxins concentration in the two regions. Values exceeding the PMTDI (provisional maximum tolerable daily intake) are shown in bold.

\begin{tabular}{|c|c|c|c|c|c|c|c|c|c|c|c|c|c|c|c|c|c|c|}
\hline \multirow{3}{*}{$\begin{array}{l}\text { Descriptive } \\
\text { Statistics }\end{array}$} & \multicolumn{16}{|c|}{ (A) Deterministic Exposure Analysis at Fixed Mycotoxin Concentration and Variable Rice Consumption. } & & \\
\hline & \multicolumn{2}{|c|}{$\mathrm{AFB}_{2}$} & \multicolumn{2}{|c|}{$\mathrm{AFB}_{1}$} & \multicolumn{2}{|c|}{ NIV } & \multicolumn{2}{|c|}{ DAS } & \multicolumn{2}{|c|}{$\mathrm{FB}_{1}$} & \multicolumn{2}{|c|}{ OTA } & \multicolumn{2}{|c|}{ DON } & \multicolumn{2}{|c|}{ HT2 } & \multicolumn{2}{|c|}{ ZEN } \\
\hline & SP & NP & SP & NP & SP & NP & SP & NP & SP & NP & SP & NP & SP & NP & SP & NP & SP & NP \\
\hline Mean & 1.09 & 1.83 & 4.16 & 7.48 & 22.1 & 40.5 & 3.19 & 4.67 & 32.8 & 62.9 & 0.931 & 1.74 & 10.9 & 17.2 & 5.36 & 9.86 & 15.5 & 24.7 \\
\hline Median & 1.00 & 1.73 & 3.79 & 7.08 & 20.2 & 38.3 & 2.91 & 4.42 & 29.9 & 59.6 & 0.850 & 1.65 & 9.98 & 16.3 & 4.88 & 9.33 & 14.2 & 23.4 \\
\hline Min. & 0.720 & 0.991 & 2.75 & 4.05 & 14.6 & 21.9 & 2.11 & 2.52 & 21.7 & 34.1 & 0.620 & 0.941 & 7.23 & 9.32 & 3.54 & 5.33 & 10.3 & 13.4 \\
\hline P75 & 1.16 & 2.16 & 4.42 & 8.86 & 23.5 & 47.9 & 3.39 & 5.52 & 34.9 & 74.5 & 0.990 & 2.06 & 11.6 & 20.4 & 5.71 & 11.6 & 16.5 & 29.3 \\
\hline P90 & 1.39 & 2.6 & 5.31 & 10.6 & 28.2 & 57.5 & 4.07 & 6.63 & 41.9 & 89.4 & 1.19 & 2.47 & 13.9 & 24.5 & 6.84 & 14.1 & 19.8 & 35.2 \\
\hline P95 & 1.86 & 2.88 & 7.08 & 11.8 & 37.7 & 63.8 & 5.43 & 7.36 & 55.9 & 99.3 & 1.59 & 2.75 & 18.6 & 27.2 & 9.12 & 15.6 & 26.5 & 39.1 \\
\hline Max. & 2.79 & 3.93 & 10.6 & 16.1 & 56.5 & 87.1 & 8.14 & 10.0 & 83.8 & 135 & 2.38 & 3.75 & 27.9 & 37.1 & 13.7 & 21.2 & 39.7 & 53.3 \\
\hline \multicolumn{19}{|c|}{ (B) Deterministic Exposure Analysis at Fixed Rice Consumption and Variable Mycotoxin Concentration. } \\
\hline \multirow{2}{*}{$\begin{array}{l}\text { Descriptive } \\
\text { Statistics }\end{array}$} & \multicolumn{2}{|c|}{$\mathbf{A F B}_{2}$} & \multicolumn{2}{|c|}{$\mathrm{AFB}_{1}$} & \multicolumn{2}{|c|}{ NIV } & \multicolumn{2}{|c|}{ DAS } & \multicolumn{2}{|c|}{$\mathbf{F B}_{1}$} & \multicolumn{2}{|c|}{ OTA } & \multicolumn{2}{|c|}{ DON } & \multicolumn{2}{|c|}{ HT2 } & \multicolumn{2}{|c|}{ ZEN } \\
\hline & SP & NP & SP & NP & SP & NP & SP & NP & SP & NP & SP & NP & SP & NP & SP & NP & SP & NP \\
\hline Mean & 1.09 & 1.83 & 4.16 & 7.48 & 22.1 & 40.5 & 3.19 & 4.67 & 32.9 & 62.9 & 0.931 & 1.74 & 10.9 & 17.2 & 5.36 & 9.86 & 15.6 & 24.7 \\
\hline Median & 0.311 & 1.67 & 4.11 & 5.60 & $<\mathrm{LOD}$ & $<\mathrm{LOD}$ & $<\mathrm{LOD}$ & $<\mathrm{LOD}$ & $<\mathrm{LOD}$ & 14.7 & $<\mathrm{LOD}$ & $<\mathrm{LOD}$ & $<\mathrm{LOD}$ & $<\mathrm{LOD}$ & $<\mathrm{LOD}$ & $<\mathrm{LOD}$ & $<\mathrm{LOD}$ & $<\mathrm{LOD}$ \\
\hline Min. & $<\mathrm{LOD}$ & $<\mathrm{LOD}$ & $<\mathrm{LOD}$ & $<\mathrm{LOD}$ & $<\mathrm{LOD}$ & $<\mathrm{LOD}$ & $<\mathrm{LOD}$ & $<\mathrm{LOD}$ & $<\mathrm{LOD}$ & $<\mathrm{LOD}$ & $<\mathrm{LOD}$ & $<\mathrm{LOD}$ & $<\mathrm{LOD}$ & $<$ LOD & $<\mathrm{LOD}$ & $<\mathrm{LOD}$ & $<\mathrm{LOD}$ & $<\mathrm{LOD}$ \\
\hline P75 & 1.73 & 3.01 & 5.93 & 10.8 & 13.4 & 40.7 & 5.04 & 8.54 & 97.8 & 131 & $<\mathrm{LOD}$ & $<\mathrm{LOD}$ & $<\mathrm{LOD}$ & $<\mathrm{LOD}$ & $<$ LOD & $<\mathrm{LOD}$ & 11.7 & 15.8 \\
\hline P90 & 2.71 & 4.54 & 11.1 & 16.9 & 91.3 & 138 & 11.4 & 15.4 & 97.8 & 143 & 1.26 & 1.70 & $<\mathrm{LOD}$ & $<$ LOD & 21.8 & 33.5 & 79.3 & 108 \\
\hline P95 & 4.44 & 6.94 & 13.5 & 19.7 & 125 & 199 & 11.5 & 15.4 & 105 & 149 & 4.93 & 15.6 & 125 & 174 & 21.8 & 60.9 & 80.5 & 116 \\
\hline Max. & 5.22 & 7.66 & 14.8 & 44.4 & 179 & 264 & 21.0 & 17.0 & 106 & 170 & 18.5 & 54.3 & 129 & 260 & 52.1 & 72.4 & 192 & 259 \\
\hline
\end{tabular}

PMTDI values (ng $/ \mathrm{kg}$ b.w. day): $\mathrm{AFB}_{1}=0.0001, \mathrm{AFB}_{2}=0.0001, \mathrm{NIV}=700, \mathrm{DAS}=100, \mathrm{FB}_{1}=2000, \mathrm{OTA}=17, \mathrm{DON}=1000, \mathrm{HT} 2=100, \mathrm{ZEN}=250$. 


\subsection{Cancer Risk and Margin of Exposure}

The risk characterization due to $\mathrm{AFB}_{1}$ exposure by rice consumption was measured using the margin of exposure (Table 7) and the liver cancer risk approach (Table 8). The margin of exposure was calculated using Bench Mark Dose Level for 10\% increased cancer risk based on the rodent data $\left(\mathrm{BMDL}_{10}\right)$ which is $170 \mathrm{ng} / \mathrm{kg}$ b.w./day [51]. An MoE greater than 10,000 is considered a low health concern [23]. The MoE values were calculated at exposures of fixed $\mathrm{AFB}_{1}$ concentration and variable rice consumption by adults and children of SP and NP at lower bound (LB) and upper bound (UB) scenarios (Table 7). According to the results, the population in NP is at a higher risk compared to that of SP. In addition, all the MoE values were $<10,000$ in both regions, indicating a high risk due to $\mathrm{AFB}_{1}$ exposure through rice consumption in Pakistan.

Table 7. Estimation of the Margin of Exposure in children and adults of South and North Punjab, Pakistan, using variable consumption data and a fixed mean $\mathrm{AFB}_{1}$ concentration considering both lower bound (LB) and upper bound (UB) scenarios.

\begin{tabular}{cccccccccc}
\hline & & \multicolumn{4}{c}{ South Punjab } & \multicolumn{4}{c}{ North Punjab } \\
\cline { 3 - 10 } $\begin{array}{c}\text { Deterministic } \\
\text { Analysis }\end{array}$ & $\begin{array}{c}\text { Descriptive } \\
\text { Levels }\end{array}$ & \multicolumn{2}{c}{ Adult } & \multicolumn{2}{c}{ Children } & \multicolumn{2}{c}{ Adult } & \multicolumn{2}{c}{ Children } \\
\cline { 3 - 10 } & & UB & LB & UB & LB & UB & LB & UB & LB \\
\hline & Mean & 38.0 & 41.7 & 37.6 & 41.2 & 23.3 & 23.7 & 22.4 & 22.9 \\
& Median & 40.2 & 44.1 & 41.2 & 45.2 & 24.9 & 25.4 & 23.7 & 24.2 \\
Fixed & Min. & 62.6 & 68.7 & 56.9 & 62.5 & 47.4 & 48.3 & 41.5 & 42.3 \\
Mycotoxin & P75 & 33.9 & 37.2 & 35.3 & 38.8 & 20.3 & 20.7 & 19.0 & 19.3 \\
concentration & P90 & 25.3 & 27.8 & 29.4 & 32.3 & 13.9 & 14.2 & 15.8 & 16.1 \\
& P95 & 23.5 & 25.8 & 22.1 & 24.2 & 13.6 & 13.8 & 14.2 & 14.5 \\
& Max. & 16.6 & 18.2 & 14.7 & 16.2 & 9.9 & 10.1 & 10.4 & 10.6 \\
\hline
\end{tabular}

$\mathrm{AFB}_{1}$, a potent human carcinogen, is synergistically linked to human primary liver cancer, highlighting a cancer burden in developing countries. The risk of liver cancer in individuals exposed to chronic hepatitis B virus (HBV) infection together with aflatoxins is 30 times higher than the risk in individuals exposed to aflatoxins only [52]. The age standardized rate (ASR) of liver cancer (HCC) is 3.6 cases per 100,000 individuals per year in the Pakistani population, with a $2.9 \%$ incidence [53]. The weighted average of hepatitis B antigen prevalence was $2.4 \%$ (range $1.7-5.5 \%$ ) in children and $2.4 \%$ (range 1.4-11\%) in the adult population [54]. Taking the HBV prevalence rate in Pakistan into account, the risk estimates of aflatoxin-induced HCC cases were calculated by the deterministic approach using a fixed mean $\mathrm{AFB}_{1}$ concentration and a variable consumption.

Table 8. Estimation of cancer risk in children and adults of South and North Punjab, Pakistan, using exposures at medium bound values of both scenarios (fixed mean $\mathrm{AFB}_{1}$ concentration with variable consumption data and fixed consumption data with variable $\mathrm{AFB}_{1}$ concentration).

\begin{tabular}{cccccc}
\hline \multirow{2}{*}{ Deterministic Analysis } & \multirow{2}{*}{ Descriptive Levels } & \multicolumn{2}{c}{ South Punjab } & \multicolumn{2}{c}{ North Punjab } \\
\cline { 3 - 6 } & & Adult & Children & Adult & Children \\
\hline & Mean & 0.070 & 0.071 & 0.122 & 0.127 \\
& Median & 0.066 & 0.064 & 0.114 & 0.120 \\
A. At fixed Mycotoxin & Min. & 0.042 & 0.047 & 0.060 & 0.069 \\
Concentration & P75 & 0.078 & 0.075 & 0.140 & 0.150 \\
& P90 & 0.105 & 0.090 & 0.205 & 0.180 \\
& P95 & 0.113 & 0.120 & 0.210 & 0.200 \\
& Max. & 0.160 & 0.180 & 0.288 & 0.273 \\
\hline
\end{tabular}


Table 8. Cont.

\begin{tabular}{cccccc}
\hline \multirow{2}{*}{ Deterministic Analysis } & \multirow{2}{*}{ Descriptive Levels } & \multicolumn{2}{c}{ South Punjab } & \multicolumn{2}{c}{ North Punjab } \\
\cline { 3 - 6 } & & Adult & Children & Adult & Children \\
\hline & Mean & 0.070 & 0.071 & 0.122 & 0.127 \\
& Median & 0.069 & 0.070 & 0.092 & 0.095 \\
B. At fixed & Min. & $<$ LOD & $<$ LOD & $<$ LOD & $<$ LOD \\
Consumption of Rice & P75 & 0.099 & 0.101 & 0.177 & 0.184 \\
& P90 & 0.186 & 0.188 & 0.276 & 0.287 \\
& P95 & 0.226 & 0.229 & 0.322 & 0.334 \\
& Max. & 0.248 & 0.251 & 0.725 & 0.752 \\
\hline
\end{tabular}

The calculated mean cancer risk in adult and child populations of SP in Pakistan were 0.070 and 0.071 cases per year per $10^{5}$ individuals, respectively, whereas the risk of development of liver cancer in adults and children of NP were calculated to be 0.122 and 0.127 cancers $/$ year $/ 10^{5} / \mathrm{ng} \mathrm{AFB}_{1} / \mathrm{kg}$ b.w. $/$ day, respectively. The results showed that, at maximum, the total liver cancer risk associated with rice consumption in Pakistan was 0.725 and 0.752 HCC cases/year/100,000 individuals in adults and children, respectively.

\section{Discussion}

\subsection{Mycotoxin Contamination}

The natural occurrence of multi-mycotoxins in rice has been studied in many regions of the world [32,33]. The present work is the first study on a multi-mycotoxin survey in rice in Pakistan. This work investigates the incidence of the major Aspergillus and Fusarium mycotoxins, as well as of the minor Alternaria mycotoxins in rice by using LC-MS/MS. In previous studies on Pakistani rice [24-31], information about only the traditional mycotoxins, such as aflatoxins and ochratoxin $\mathrm{A}$, was reported. The occurrence of $\mathrm{AFB}_{1}$ and OTA reported in Pakistani rice was more or less similar [26,29]. A previous study on Pakistani rice $(n=62)$ recorded that $47 \%$ and $37 \%$ of samples contained $\mathrm{AFB}_{1}$ and OTA in a concentration range of $0.04-21.3$ and $0.6-25.4 \mu \mathrm{g} / \mathrm{kg}$, respectively [26]. Furthermore, our earlier study demonstrated that 56 and $50 \%$ of rice samples were positive for aflatoxins and OTA, with levels of contamination ranging from 0.05 to 24 and 0.06 to $15 \mu \mathrm{g} / \mathrm{kg}$, respectively [29].

Studies on multi-mycotoxin contamination of rice, however, have been conducted in some other countries [4,55-59]. A high incidence of multiple mycotoxins was found in Nigerian, Turkish, Chinese, and Indian rice [4,56,58]. A study showed $100 \%$ frequency of positive samples $(n=21)$ for AFs in Nigerian rice. The levels of $\mathrm{AFB}_{1}$ and $\mathrm{AFB}_{2}$ were in the range of $4.1-309 \mu \mathrm{g} / \mathrm{kg}(37.2 \mu \mathrm{g} / \mathrm{kg}$ mean level) and 1.3-24.2 $\mu \mathrm{g} / \mathrm{kg}$ (mean level of $8.3 \mu \mathrm{g} / \mathrm{kg}$ ), respectively. OTA level was in the range of $<\mathrm{LOD}-341.3 \mu \mathrm{g} / \mathrm{kg}$ in $67 \%$ of the samples, with a mean level of $141.7 \mu \mathrm{g} / \mathrm{kg}$, while ZEN was prevalent in $52 \%$ of the samples, with a mean level of $10.6 \mu \mathrm{g} / \mathrm{kg}$ (in the range of $<\mathrm{LOD}-41.9 \mu \mathrm{g} / \mathrm{kg}$ ). The contamination level for DON was in the range of $<$ LOD $-112.2 \mu \mathrm{g} / \mathrm{kg}$ in $24 \%$ of the samples (mean $18.9 \mu \mathrm{g} / \mathrm{kg}$ ). Moreover, $14 \%$ of the samples were positive for $\mathrm{FB}_{1}$, with concentrations in the range of $0.4-4.4 \mu \mathrm{g} / \mathrm{kg}$ and a mean of $0.2 \mu \mathrm{g} / \mathrm{kg}$ [58]. The levels of AFs and OTA contamination in Turkish rice were found to be in the range of 0.05 to 21.4 and 0.025 to $80.7 \mu \mathrm{g} / \mathrm{kg}$, with a $58 \%$ and $72 \%$ incidence rate, respectively [56]. The data from an Indian study revealed the content of $\mathrm{AFB}_{1}$ to be in the range of 0.1 to $308 \mu \mathrm{g} / \mathrm{kg}$ in $68 \%$ of rice samples $(n=1600)$ [4].

Some studies also reported lower contamination levels of mycotoxins in rice in different countries as compared to the present study [55,57]. A study on rice samples $(n=9)$ from Qatar, observed levels of AFs in the range of $0.14-0.24 \mu \mathrm{g} / \mathrm{kg}$ and of OTA in the range of $1.65-1.95 \mu \mathrm{g} / \mathrm{kg}$. The level of DON found in one sample was $142.31 \mu \mathrm{g} / \mathrm{kg}$ and the level of ZEN was from 0.18 to $1.41 \mu \mathrm{g} / \mathrm{kg}$ [55]. A survey of rice samples $(n=199)$ sold in Canada revealed that $50 \%, 22 \%$, and $8 \%$ of rice samples were contaminated with $\mathrm{AFB}_{1}, \mathrm{OTA}$, and $\mathrm{FB}_{1}$, respectively. The concentration levels of $\mathrm{AFB}_{1}, \mathrm{OTA}$, and 
$\mathrm{FB}_{1}$ were lower as compared to the present study, ranging between $0.002-7.1 \mu \mathrm{g} / \mathrm{kg}, 0.05-0.49 \mu \mathrm{g} / \mathrm{kg}$, and $0.7-14 \mu \mathrm{g} / \mathrm{kg}$, respectively [57].

In the present study, a higher incidence of Aspergillus toxins was observed in comparison to Fusarium mycotoxins. However, in Korean brown rice, an opposite trend was reported, as the frequencies of AFs, ZEN, NIV, and DON were $7.5 \%, 84 \%, 29 \%$, and $1.3 \%$, respectively, whereas the levels of contamination were estimated from 0.7 to $2.7 \mu \mathrm{g} / \mathrm{kg}$ (AFs), from 4.2 to $201.3 \mu \mathrm{g} / \mathrm{kg}$ (ZEN), from 7.7 to $349 \mu \mathrm{g} / \mathrm{kg}$ (NIV), and $43.2 \mu \mathrm{g} / \mathrm{kg}$ (DON) [59]. The variation in mycotoxin contamination in rice from different regions may be due to differences in climate as well as differences in the prevalent toxigenic microflora influenced by different agricultural practices and storage conditions [33].

\subsection{Consumption of Rice}

Consumption of rice in Iran (107 g/day per person) [34], Japan (157 g/day per capita), and China (183 g/day per capita) are comparable to our consumption results but not to the very high rice consumption (377 g/head/day) in Thailand [60].

\subsection{Effect of Cooking on $A F B_{1}$ and $A F B_{2}$ Levels}

The reduction of aflatoxins during the cooking process might occur because of its removal during washing, binding to a food matrix, or degradation or modification to unknown products during the aqueous heating process. A study reported a $14.7-15.3 \%$ reduction of aflatoxins with washing similar to the results of the present study [61]. The reduction of aflatoxins during rice cooking was reported by previous studies [62-65]. Ordinary cooking of $\mathrm{AFB}_{1}$-contaminated rice gave an average reduction of $34 \%$ [64], while a $78-88 \%$ reduction was observed with pressure cooking [63]. In another study, cooking of $\mathrm{AFB}_{1}$-contaminated rice showed $87.5 \%$ (cooking in excess water), $84 \%$ (ordinary cooking), and $72.5 \%$ (microwave cooking) reduction of $\mathrm{AFB}_{1}$ [62]. In contrast, a low level of $\mathrm{AFB}_{1}$ reduction $(24.8 \%)$ was observed with two cooking methods common in Iran [65].

\subsection{Exposure Assessment of Mycotoxins in Pakistani Children and Adults}

Average $\mathrm{AFB}_{1}$ intakes of 22.2-22.3 ng/kg b.w./day [26] and 19.1-26.6 ng/kg b.w/ day [25] were reported in previous studies. Our study results showed lower exposure compared to these previous studies, whereas in the high consumption group the exposure values in our study (42.77 and $44.36 \mathrm{ng} / \mathrm{kg}$ b.w. day) were higher. This might be due to differences in sampling, levels of contamination of AFs in rice, and consumption data considered during these studies. By comparing the previous studies conducted in different countries, our results match with the estimated mean $\mathrm{AFB}_{1}$ exposure due to rice consumption in Korea (0.89-5.37 ng/ kg b.w./day) [41], Brazil (6.5-6.6 ng/kg b.w./day) [66], and Nigeria (5.2 ng/kg b.w./day) [37]. In contrast, in Japan, the observed dietary exposure of $\mathrm{AFB}_{1}$ was 1.78 and $1.20 \mathrm{ng} / \mathrm{kg}$ b.w./day at the 95th percentile level in children aged 7-14 years and in adults, respectively [67].

Because of the low contamination levels, the dietary exposures to $\mathrm{AFB}_{1}$ from rice and wheat intake in French adults (<LOD—0.018 ng/kg b.w./day) and children (<LOD—0.035 ng/kg b.w./day) [38], as well as in the Lebanese population $(0.63-0.66 \mathrm{ng} / \mathrm{kg} \mathrm{b.w} /$ day) based on total diet intake were lower than those observe in the present study [68]. The current data is higher than the reported mean dietary exposure to $\mathrm{AFB}_{1}(0.8$ and $0.12 \mathrm{ng} / \mathrm{kg}$ b.w. $/$ day) by rice consumption in Thailand in the years 2012 and 2013 [40]. Also, the dietary exposure to $\mathrm{AFB}_{1}(0.033 \mathrm{ng} / \mathrm{kg}$ b.w./day) in Morocco [44] and that to total AFs in French adults (0.014 ng/kg b.w./day) and children (0.077 ng/kg b.w./day) [39] are lower than those observed in the current study. On the other hand, the mean $\mathrm{AFB}_{1}$ exposure values of $21.7 \mathrm{ng} / \mathrm{kg}$ b.w./day in Northern Vietnam adults, $33.7 \mathrm{ng} / \mathrm{kg}$ b.w./day in children [43], $22.2 \mathrm{ng} / \mathrm{kg}$ b.w./day in adults of Lao Cai province of Vietnam [42], 5.8-76 ng/ $\mathrm{kg}$ b.w./day (LB-UB) in the Chinese population [69], and $14 \mathrm{ng} / \mathrm{kg}$ b.w./day in the African country Gambia were higher than those observed in our study, because of high rice consumption and contamination levels [45]. 
The mean dietary exposures of $1.50 \mathrm{ng} / \mathrm{kg}$ b.w./ day of OTA in the Nigerian population [37] and of $4.28 \mathrm{ng} / \mathrm{kg} \mathrm{b.w./day} \mathrm{in} \mathrm{the} \mathrm{Lebanese} \mathrm{population} \mathrm{[68]} \mathrm{were} \mathrm{comparable} \mathrm{to} \mathrm{thos} \mathrm{eobserved} \mathrm{in} \mathrm{this} \mathrm{study.}$ The higher mean dietary exposures to OTA $(24.2-24.7 \mathrm{ng} / \mathrm{kg}$ b.w. / day) by rice consumption reported in Pakistan [26] and in Vietnam (7.9 ng/ kg b.w./day) were due to relatively higher contamination levels of OTA in rice [42]. The mean dietary exposure of OTA was higher in Chinese adults (4.62 ng/ kg b.w./day) and children (13.9 $\mathrm{ng} / \mathrm{kg}$ b.w./day) because of a higher consumption level of cereals [70]. The mean OTA exposure values of $0.0004 \mathrm{ng} / \mathrm{kg}$ b.w./day in US adults and $0.001 \mathrm{ng} / \mathrm{kg}$ b.w./day in US children aged $>6-18$ years [35], $0.02 \mathrm{ng} / \mathrm{kg}$ b.w./day in Turkish rice consumers [36], $0.17 \mathrm{ng} / \mathrm{kg}$ b.w./day in Spain [46], $0.08 \mathrm{ng} / \mathrm{kg}$ b.w./day in French adults, $0.19 \mathrm{ng} / \mathrm{kg}$ b.w./day in French children [40], and $0.0428 \mathrm{ng} / \mathrm{kg}$ b.w./day in Moroccans [44] by rice consumption were lower than those reported in our study.

Similar results were found for DON mean dietary exposure of $9.51 \mathrm{ng} / \mathrm{kg}$ b.w. $/$ day in French adults and $23.7 \mathrm{ng} / \mathrm{kg}$ b.w./day in children by rice intake [39], as well as $5.7-6.6 \mathrm{ng} / \mathrm{kg}$ b.w./day in French adults and 14.3-16.0 ng/kg b.w./day in children by rice and wheat intake [38]. Through cereal intake, a higher dietary exposure of DON was reported for Chinese adults ( $309 \mathrm{ng} / \mathrm{kg} \mathrm{b.w./day)}$ and children ( $927 \mathrm{ng} / \mathrm{kg}$ b.w./day) compared to what found in the present study [70]. The estimated mean exposure values for DON, $5.97 \mathrm{ng} / \mathrm{kg}$ b.w./day in the Nigerian population [37] and $0.18 \mathrm{ng} / \mathrm{kg}$ b.w./day in the Moroccan population [44], and $1.56 \mathrm{ng} / \mathrm{kg}$ b.w./day in the Lebanese population [68] were lower than those reported in the current study data. The mean estimated exposure values of $3.8 \mathrm{ng} / \mathrm{kg}$ b.w./day in French adults, $42.5 \mathrm{ng} / \mathrm{kg}$ b.w/ day in children [40], $0.042 \mathrm{ng} / \mathrm{kg}$ b.w./day in the Moroccan population [45], and $19.13 \mathrm{ng} / \mathrm{kg}$ b.w./day in the Nigerian population [37] for FBs by rice intake were lower than those found in the present study. In contrast, a higher FBs mean exposure of $536 \mathrm{ng} / \mathrm{kg}$ b.w./day in Northern Vietnam adults and $1019 \mathrm{ng} / \mathrm{kg}$ b.w./day in children was reported [43].

In the present study, NIV exposure results are similar to those reported for the Nigerian population (20.81 ng/kg b.w./day) [37]. The present study showed a higher level of the estimated mean exposure for NIV by rice intake as compared to that reported in French adults $(4.86 \mathrm{ng} / \mathrm{kg}$ b.w./day) and children (11.2 ng/kg b.w./day) [39] and in the Moroccan population (6.12 ng/kg b.w./day) [44], as well as to the mean exposure ranges (UB-LB) of NIV in French adults (1.88-2.8 ng/ $\mathrm{kg}$ b.w./day) and children (4.76-6.43 ng/kg b.w./day) [39]. Data on the exposure to HT-2 and DAS is scant in the literature. In this study, the HT2 toxin dietary intakes were higher than the mean estimated exposure for the sum of HT2 and T2 $(0.361 \mathrm{ng} / \mathrm{kg}$ b.w./day) in the Moroccan population [44] and the mean exposure ranges (UB-LB) for HT2 in French adults (0.19-1.53 ng $/ \mathrm{kg}$ b.w./day) and children (0.16-1.42 ng/kg b.w./day) [38]. The mean estimated exposure (0.101 ng $/ \mathrm{kg}$ b.w./day) of DAS by rice intake in the Moroccan population [44] was lower as compared to our values.

The mean dietary exposure values of $2 \mathrm{ng} / \mathrm{kg}$ b.w./day for ZEN by rice consumption in Iranian people [34] and in French adults (1.63 ng/kg b.w./day) and children (3.75 ng/kg b.w./day) were lower as compared to those found in our study [39]. Also, the mean estimated exposure ranges (UB-LB) for ZEN by rice and wheat products intake in French adults $(0.06-0.7 \mathrm{ng} / \mathrm{kg}$ b.w./day) and children (0.16-1.42 ng/kg b.w./day) were lower than those observed in the present study [38]. A higher estimated mean exposure of $157.36 \mathrm{ng} / \mathrm{kg}$ b.w./day of ZEN was reported in the Nigerian population [37] by rice intake, and of $155 \mathrm{ng} / \mathrm{kg}$ b.w./day in Chinese adults and of $464 \mathrm{ng} / \mathrm{kg}$ b.w./day in Chinese children through cereal intake [70].

These discrepancies in exposure estimations are due to the variability in food consumption levels, differences in contamination data, cooking effects, and differences in the analytical techniques used in the reported studies.

\subsection{Cancer Risk and Margin of Exposure}

Based on these results, it is obvious that the intake of contaminated rice is of great public health concern. Our results for the estimated cancer risk and $\mathrm{MoE}$ due to $\mathrm{AFB}_{1}$ intake by rice consumption 
are comparable with those of previous studies reported for Japan [67] and Thailand [40]. The study for Japan measured a cancer risk of 0.031 cancer/year $/ 10^{5}$, and a MoE of 141 for children (age 7-14 years) resulting from $\mathrm{AFB}_{1}$ intake by rice consumption, while in adults the values of cancer risk and margin of exposure were 0.021 cancer/year $/ 10^{5}$ and $209 \mathrm{MoE}$, respectively [67]. The mean cancer risk and margin of exposure due to $\mathrm{AFB}_{1}$ intake through colored and brown rice in all age groups of Thailand were in the range of $0.010-0.039$ cancer/year $/ 10^{5}$, with 5\% HBV prevalence rate [40].

The mean cancer risk and margin of exposure due to total dietary $\mathrm{AFB}_{1}$ intake in Brazil [66] and Malaysia [71] were also similar to those determined in our study. The mean cancer risk and margin of exposure in Brazil, with a $0.37 \%$ prevalence rate of $\mathrm{HBV}$, were 0.0753 cancer $/$ year $/ 10^{5}$ and $25 \mathrm{MoE}$, respectively [66]. The liver cancer risk in Malaysia by total dietary $\mathrm{AFB}_{1}$ calculated by eliminating high contamination data was $0.01-0.26$ cancer/100,000 people/year, with a $0.2-2.1 \%$ contribution to liver cancer cases, while, by adding the high contamination data, the value increased to 0.61-0.85 cancer/year $10^{5}$ people, raising the contribution to liver cancer cases up to 12.4-17.3\% [71].

The cancer risk and margin of exposure due to $\mathrm{AFB}_{1}$ intake through rice in Chinese [69], Vietnamese [42], and African populations [45] were higher as compared to those found in the present study. This might be because of high contamination levels of $\mathrm{AFB}_{1}$ in rice and high consumption levels, as well as high prevalence rate of $\mathrm{HBV}$ in those countries. The cancer risk and margin of exposure in the Chinese population were 0.2-2.65 (UB-LB) cancer/year/10 5 people and 1.8-24.1 (UB-LB) MoE, respectively, using a 14.3\% prevalence rate of HBV [69]. The mean cancer risk and margin of exposure in Vietnam were 1.51 cancer/year $/ 10^{5}$ individuals and $8 \mathrm{MoE}$, respectively, using a $20 \%$ prevalence rate of HBV [42]. Another study in Africa reported a cancer risk of 1.1 cancer/year $/ 10^{5}$ people considering a $25 \% \mathrm{HBV}$ prevalence rate and an MoE of 12.1 for Gambia [45]. The estimated mean cancer risk of 2.3 cancer/year $/ 10^{5}$ people for the consumers was reported for Northern Vietnam, considering a $20 \% \mathrm{HBV}$ prevalence rate, while, in adults, the value of cancer risk was 1.2 cancer $/$ year $/ 10^{5}$ people [43]. Because of the low contamination level in foods, the estimated dietary cancer risk in Japan is much lower as compared to our study results: even at the 99.9th percentile, it was 0.00059-0.00067 cancer/year $/ 10^{5}$ population assuming a $1 \% \mathrm{HBV}$ prevalence rate [72].

To reduce the synergistic effect of HBV and aflatoxins, the improvement in HBV vaccination as well as measures for the reduction of aflatoxin contamination in foods are necessary. The risk characterization of multiple-mycotoxins in rice will be useful for setting mycotoxin priority in adopting control measures. Moreover, the measured mycotoxin exposure due to rice in this study can be used in future total dietary exposure estimates in Pakistan, as the burden of cancer risk depends on the cumulative exposure. In addition to HBV and aflatoxins, Hepatitic C Virus (HCV) may also be taken into account in future coexposure studies, since it is one of the leading factors involved in HCC. Notably, HBV [54] and HCV [73] are highly prevalent in the Pakistani population.

\section{Conclusions}

The study measured the levels of multi-mycotoxin contamination in rice samples using a validated multi-mycotoxin LC-MS/MS method. The risk assessment of mycotoxins by rice intake in adults and children of the Pakistani population in SP and NP regions was performed after attaining consumption data of rice by conducting food frequency questionnaires. The mycotoxin contamination profile of Pakistani rice showed the prevalence of $\mathrm{AFB}_{2}, \mathrm{AFB}_{1}, \mathrm{NIV}, \mathrm{DAS}, \mathrm{FB}_{1}, \mathrm{OTA}, \mathrm{DON}, \mathrm{HT} 2$, and ZEN. Among the evaluated rice cooking recipes, Biryani demonstrated the highest degradation of $\mathrm{AFB}_{2}$ $(63 \%)$ and $\mathrm{AFB}_{1}(51 \%)$. Our results indicate that dietary exposure to mycotoxins through rice was higher in children as compared to adults, and higher in NP in comparison to SP. The MoE of $\mathrm{AFB}_{1}$ was remarkably lower than the recommended safe limits. Moreover, there is a potential risk, due to rice consumption, of developing aflatoxin-induced hepatocellular carcinoma (HCC) in Pakistan. The Pakistani population is not exposed to a single mycotoxin but faces exposure to multiple mycotoxins. This study highlights the need to establish regulatory guidelines regarding the prevalence of mycotoxins in Pakistani foods, and a regular monitoring of highly consumed foodstuff, especially 
rice and cereals, is suggested. A cumulative risk assessment from the exposures of multi-mycotoxins, especially in the HBV- and HCV-infected population, also needs to be thoroughly studied in the future.

\section{Materials and Methods}

\subsection{Reagents and Chemicals}

Ochratoxin $\mathrm{A}(\mathrm{OTA}=10 \mu \mathrm{g} / \mathrm{mL})$, aflatoxin mix $\left(\mathrm{AFB}_{1}, \mathrm{AFB}_{2}, \mathrm{AFG}_{1}, \mathrm{AFG}_{2}=20 \mu \mathrm{g} / \mathrm{mL}\right)$, deoxynivalenol $(\mathrm{DON}=100 \mu \mathrm{g} / \mathrm{mL})$, zearalenone $(\mathrm{ZEN}=100 \mu \mathrm{g} / \mathrm{mL})$, Fumonisin $\operatorname{mix}\left(\mathrm{FB}_{1}, \mathrm{FB}_{2}=50 \mu \mathrm{g} / \mathrm{mL}\right)$, nivalenol $(\mathrm{NIV}=100 \mu \mathrm{g} / \mathrm{mL})$, neosolaniol $(\mathrm{NEO}=100 \mu \mathrm{g} / \mathrm{mL})$, deepoxy-deoxynivalenol $(\mathrm{DOM}=50 \mu \mathrm{g} / \mathrm{mL})$, $\mathrm{T}-2$ toxin $(\mathrm{T} 2=100 \mu \mathrm{g} / \mathrm{mL})$, HT-2 toxin $(\mathrm{HT} 2=100 \mu \mathrm{g} / \mathrm{mL})$, 3-acetyldeoxynivalenol (3-ADON = 100 $\mu \mathrm{g} / \mathrm{mL}$ ), diacetoxyscirpenol (DAS $=100 \mu \mathrm{g} / \mathrm{mL}$ ), 15-acetyldeoxynivalenol (15-ADON = $100 \mu \mathrm{g} / \mathrm{mL}$ ), fusarenon $X(F X=100 \mu \mathrm{g} / \mathrm{mL})$, and sterigmatocystin (STERIG $=50 \mu \mathrm{g} / \mathrm{mL}$ ) were obtained as certified mycotoxin standard solutions in acetonitrile from Biopure (RomerLabs, Tulln, Austria). Fumonisin $B_{3}$ $\left(\mathrm{FB}_{3}\right)$ was obtained from Promec unit (Tygerberg, South Africa). Zearalanone (ZAN), alternariol (AOH) and alternariol monomethylether (AME) were purchased from Sigma and roquefortine C (ROQ-C) from Alexis Biochemicals (Enzo Life Sciences BVBA, Zandhoven, Belgium). The stock solution of $\mathrm{FB}_{3}(1 \mathrm{mg} / \mathrm{mL})$ was made in acetonitrile/water $(50 / 50, v / v)$. The stock solutions of AOH and AME ( $1 \mathrm{mg} / \mathrm{mL})$ were prepared in methanol/dimethylformamide $(60 / 40, v / v)$. ROQ-C and ZAN stock soution $(1 \mathrm{mg} / \mathrm{mL})$ were prepared in methanol. The stock solution of $\mathrm{FB}_{3}$ was stored at $4{ }^{\circ} \mathrm{C}$, while all the others were stored at $-20^{\circ} \mathrm{C}$ for one year or until the expiration date. Working solutions were made by diluting the stock solutions in methanol and were stored at $-20{ }^{\circ} \mathrm{C}$ for 3 months. A working solution of a standard mixture was prepared with the following concentrations: $\mathrm{OTA}, \mathrm{AFB}_{1}, \mathrm{AFB}_{2}$, $\mathrm{AFG}_{1}$, and $\mathrm{AFG}_{2}(0.2 \mathrm{ng} / \mu \mathrm{L})$; DAS $(0.5 \mathrm{ng} / \mu \mathrm{L})$; ROQ-C $(1 \mathrm{ng} / \mu \mathrm{L}) ; 15-\mathrm{ADON}(2.5 \mathrm{ng} / \mu \mathrm{L}) ; 3-\mathrm{ADON}$ and STREG (5 ng/ $\mu \mathrm{L}) ; \mathrm{ZEN}, \mathrm{NEO}$, and AOH (10 ng/ $\mu \mathrm{L})$; T2-toxin and HT2-toxin (2.5 ng/uL); NIV, Fux-X, and AME (20 ng/ $\mu \mathrm{L}) ; \mathrm{FB}_{3}(25 \mathrm{ng} / \mu \mathrm{L}) ; \mathrm{DON}, \mathrm{FB}_{1}$, and $\mathrm{FB}_{2}(40 \mathrm{ng} / \mu \mathrm{L})$.

\subsection{Sampling and Food Consumption Data}

Polished rice of all varieties and brands, intended for human consumption, was randomly purchased in the quantity of $1 \mathrm{~kg}$ from different wholesale markets, super markets, and small shops located in ten districts of two different agroecological zones of Punjab (North and South Punjab), Pakistan, during the year 2015. Ninety samples from each region were collected (Figure 2). The average rainfall in South Punjab (SP) and North Punjab (NP) are between $22.65 \mathrm{~mm}$ and $66.99 \mathrm{~mm}$, respectively. The average annual temperatures in SP and NP are $26{ }^{\circ} \mathrm{C}$ and $24{ }^{\circ} \mathrm{C}$, respectively. The location of $\mathrm{SP}$ and NP in coordinates (latitude and longitude) are between $28-30^{\circ} \mathrm{N}, 70-71^{\circ} \mathrm{E}$, and $31-33^{\circ} \mathrm{N}$, $72-74^{\circ} \mathrm{E}$, respectively $[74,75]$.

All samples were ground using an M 20-grinder (Ika-Werke, Staufen, Germany) and kept in plastic bags at $-20^{\circ} \mathrm{C}$ before mycotoxin determination. To obtain accurate exposure estimates, rice consumption data were obtained by conducting a survey in southern and northern Punjab regions of Pakistan. A FFQ was prepared, and individuals and families were interviewed. Portion-size pictures (small, medium, and large servings of cooked rice, i.e., $50 \mathrm{~g}, 75 \mathrm{~g}, 100 \mathrm{~g}$ of uncooked rice) were used to gather information on the rice intake, and the actual weight of each portion size was measured. The diet intake information for one week was gathered from the participants, and the mean daily rice intake of each individual was calculated (per $\mathrm{kg}$ of body weight per day). The proportions of participants from South Punjab (SP) and North Punjab (NP) regions in gathering the consumption data were $48 \%$ and $52 \%$, respectively. The gender distribution of the participants was $48 \%$ male and $52 \%$ female. In total, 548 individuals in the adult category were interviewed, and the data of 467 individuals in the children category (age 7-15 years) was gathered by interviewing either the children or the female family head. Finally, the data from both regions was arranged separately for each category (adults and children) to get the mean, median, minimum, maximum, and percentile (P75, P90, P95) intake 
of rice. Furthermore, the generated consumption data was used in calculating the dietary exposure to mycotoxins.

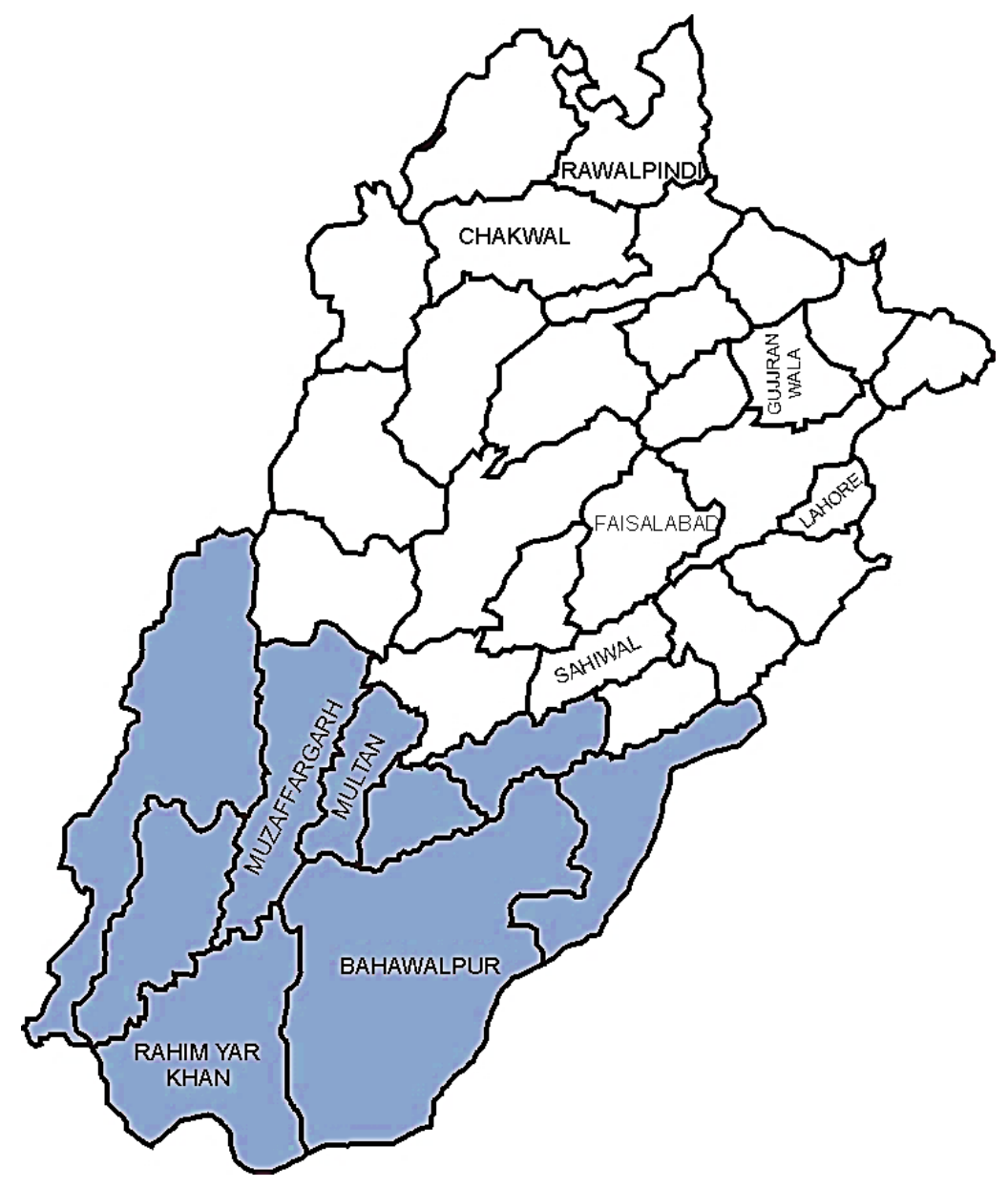

Figure 2. Map of Punjab province, Pakistan $\left(30^{\circ} 00^{\prime} \mathrm{N} 70^{\circ} 00^{\prime} \mathrm{E}\right)$. The sampling points and districts are labelled. The colored region represents the southern irrigated zone (SP), while the white region shows the central-northern irrigated zone (NP).

\subsection{Sample Preparation}

The sample extraction methodology described by Monbaliu et al. [76] was followed. Internal standards were added to the samples before extraction. Five grams of the rice sample was extracted with $20 \mathrm{~mL}$ of acetonitrile/water/acetic acid $(79 / 20 / 1, v / v / v)$ by agitating on a vertical shaker for $1 \mathrm{~h}$ and centrifuged for $15 \mathrm{~min}$ at $3300 \mathrm{~g}$. The supernatant was subjected to cleanup by octadecyl $\left(\mathrm{C}_{18}\right)$ solid phase extraction (SPE) column (Grace octadecyl C18, Lokeren, Belgium) on a vacuum elution manifold after conditioning with $10 \mathrm{~mL}$ of the extraction solvent-acetonitrile/water/acetic acid (79/20/1, $v / v / v)$. The extraction was performed a second time by adding $5 \mathrm{~mL}$ of the extraction solvent to the samples. The eluate was collected in a $25 \mathrm{~mL}$ volumetric flask. The volume was adjusted with the extraction solvent. The extract was defatted with $10 \mathrm{~mL} n$-hexane. Then the extract was split into two parts to perform two different modes of cleanup. In the first cleanup, $12.5 \mathrm{~mL}$ of the defatted extract was diluted with $27.5 \mathrm{~mL}$ of acetonitrile/acetic acid $(99 / 1, v / v)$, and $30 \mathrm{~mL}$ of this extract was passed through Multisep226, Afla-ZON ${ }^{+}$Multifunctional columns from Romers Lab. (Gernsheim, Germany), followed by washing with $5 \mathrm{~mL}$ of acetonitrile/acetic acid $(99 / 1, v / v)$. In the second cleanup mode, the defatted extract $(10 \mathrm{~mL})$ was filtered through a Whatman glass microfilter (VWR International, Zaventem, Belgium), and $2 \mathrm{~mL}$ of this filtered extract was combined with the MultiSep 226 eluate. 
The combined eluates were evaporated, and the residue was dissolved in $150 \mu \mathrm{L}$ of mobile phase containing methanol/water/acetic acid (57.2/41.8/1, v/v/v) and $5 \mathrm{mM}$ ammonium acetate. Before LC-MS/MS analysis, the resulting solution was ultracentrifuged for $5 \mathrm{~min}$ at 14,000 $\mathrm{g}$ using ultra free-MC centrifugal filters (Bedford, MA, USA).

\subsection{Analysis by LC-MS/MS}

A micromass Quatro Micro triple quadrupole mass spectrometer (Waters, Milford, MA, USA) equipped with a Waters Acquity UPLC system was used to analyze the samples, and the Masslynx (4.1) software (Micromass, Manchester, UK) was used for data processing. The analytical column was a Symmetry C18, $5 \mu \mathrm{m}, 2.1 \times 150 \mathrm{~mm}$ (Waters, Zellik, Belgium), with a guard column of Waters Sentry $3.5 \mu \mathrm{m} 2.1 \times 10 \mathrm{~mm}$ (Waters, Zellik, Belgium). The column and autosampler temperature was kept at $30^{\circ} \mathrm{C}$, and $20 \mu \mathrm{L}$ was injected. Capillary voltage was set at $3.2 \mathrm{kV}$ with a source voltage of $150{ }^{\circ} \mathrm{C}$ and a $350^{\circ} \mathrm{C}$ desolvation temperature. Liquid chromatography conditions (mobile phase composition and gradient) and MS parameters were followed as described by Monbaliu et al. [77].

\subsection{Quality Control and Quality Assurance}

A set of performance characteristics that were in compliance with the recommendations defined by EU Commission Regulation EC/401/2006 was evaluated [49]. Deepoxy-deoxynivalenol (DOM) and zearalanone (ZAN), structural analogues of the type-B trichothecenes, and ZEN were used as internal standards in the multi-mycotoxin determination to compensate for matrix effects and for losses during extraction and cleanup. For each mycotoxin, a spiking experiment was performed at five concentration levels except for aflatoxins, which were spiked at six different levels each day in triplicate for four validation days (Table A1). The validation parameters assessed were: linearity, apparent recovery, limit of detection (LOD), limit of quantification (LOQ), intraday repeatability $\left(\mathrm{RSD}_{\mathrm{r}}\right)$, interday repeatability $\left(\mathrm{RSD}_{\mathrm{R}}\right)$, and expanded uncertainty. The linearity was tested graphically using a scatter plot, and the linear regression model was evaluated using a lack-of-fit test. The apparent recovery was calculated by dividing the observed value (quantified using calibration plot) by the spiked level. The sensitivity of the method was estimated by LOD. A series of blank rice samples spiked at low concentration levels were used to estimate LODs and LOQs, which provided a signal to noise ratio of 3:1 and 10:1 for the weakest transitions in LC-MS/MS chromatograms for each of the analyte, respectively. The precision in terms of intraday repeatability (the analysis of three replicates on the same day) and interday repeatability (the analysis of three replicates on four different days) was calculated using relative the standard deviation (RSD) at the spiked concentration levels $(n=5)$. The expanded measurement uncertainty (U) was obtained by multiplying the combined standard uncertainty (uc) by a coverage factor $k=2$, based on the desired level of confidence of approximately $95 \%$, where the uc was an estimated standard deviation calculated as the positive square root of the total variance obtained by combining the intralaboratory repeatability (sR), the uncertainty associated with the purity of the standards ( $\mathrm{U}(\mathrm{Cref}))$, and the uncertainty associated with the mean recovery (sbias).

\subsection{Cooking of Rice by Pakistani Recipes}

Three most common local cooking methods of rice in Pakistan were evaluated for their efficiency in the degradation of $\mathrm{AFB}_{1}$ and $\mathrm{AFB}_{2}$. Negative control samples were also washed and cooked as in each treatment, and spiked with known concentrations of standards after cooking. The aim was to make matrix-matched calibration curves and quantify the levels of $\mathrm{AFB}_{1}$ and $\mathrm{AFB}_{2}$ in the treated samples. The positive controls were samples of naturally contaminated uncooked rice that were used for comparison of the treatments to conclude the percentage of AFs degradation.

Naturally contaminated rice samples (100 g each in triplicate for each treatment) were washed with water $(200 \mathrm{~mL})$ three times, soaked in $200 \mathrm{~mL}$ of water for $20 \mathrm{~min}$, and finally the water was completely removed. This washing step was similar in all treatments. For the first recipe (treatment) of boiled rice, the washed rice was added to boiling water $(200 \mathrm{~mL})$ and cooked for about $20 \mathrm{~min}$. In the 
second recipe (pulao), first a curry (ingredients: oil, onion, ginger and garlic paste, tomato, boiled chicken, and salt and chili) was prepared, and $200 \mathrm{~mL}$ of water was added to the curry. On boiling, the washed rice was added to the mixture and cooked for $10 \mathrm{~min}$ at high flame and $20 \mathrm{~min}$ at low flame, while covering it tightly with a lid. For the third recipe (Biryani), the washed rice was boiled in excess water for $5 \mathrm{~min}$, and the water was removed. The curry was prepared separately, having the same ingredients as those in pulao with additional yogurt and spices like cumin, pepper, cloves, cinnamon, cardamom, bay leaves, coriander, and mint leaves. Layers of curry and the boiled rice, alternatively on top of each other, were made in a pot and further cooked for 20 min at low flame after covering tightly with a lid. The cooked rice was cooled down and freeze dried. Then the samples were ground and analyzed for aflatoxin levels after sample preparation, following the methodology described by Majeed et al. [78].

\subsection{Dietary Exposure Assessment}

The dietary exposure of mycotoxins was calculated by a deterministic risk analysis (Equation (1)).

Dietary Exposure = concentration of mycotoxin $\times$ daily rice intake per $\mathrm{kg}$ of body weight

The left-censored mycotoxin contamination data related to the non-detects (ND), and those below the limit of quantification (<LOQ) can be a source of uncertainty in exposure models [79]. So, three different scenarios (lower bound, medium bound, and upper bound) were incorporated in this study to cope with the uncertainty, following the approach described by EFSA [80]. The dietary exposure levels were estimated considering two approaches, using a fixed mycotoxin concentration and variable values (mean, median, maximum, and probability values) of consumption level, and using fixed consumption levels with variable values (mean, median, maximum, and probability values) of mycotoxin levels. In each approach, all three scenarios were considered: Upper bound ( $<\mathrm{LOQ}=\mathrm{LOQ})$, Medium bound $(<\mathrm{LOQ}=1 / 2 \mathrm{LOQ})$, and lower bound $(<\mathrm{LOQ}=0)$.

\subsection{Risk Characterization}

The risk characterization of the genotoxic aflatoxins was performed by both margin of exposure MoE [23] and cancer risk approaches [22]. The MoE was estimated (Equation (2)) by the ratio of Bench Mark Dose Level (BMDL) that causes a 10\% increase in the cancer incidence in rodents $\left(\mathrm{BMDL}_{10}=170 \mathrm{ng} / \mathrm{kg}\right.$ b.w. day) and the exposure to $\mathrm{AFB}_{1}$ [23].

$$
\text { Margin of exposure }=\mathrm{BMDL}_{10} / \text { exposure }(\mathrm{ng} / \mathrm{kg} \text { b.w. day) }
$$

The risk of $\mathrm{AFB}_{1}$-induced cancer (hepatocellular carcinoma, HCC) was calculated (Equation (3)) by multiplying the probability of cancer with the $\mathrm{AFB}_{1}$ exposure estimates of min, max, mean, and percentiles in both upper and lower bound scenarios for each category in both regions. Here, cancer potency $\mathrm{P}_{\text {cancer }}$ (Equation (4)) deals with the percentage of both carriers (\%Pop.HBsAg $\left.{ }^{+}=0.024\right)$ and noncarriers (\%Pop.HBsAg ${ }^{-}=0.976$ ) of HBV infection in the Pakistani population, that is 2.4\% [54], as well as with the carcinogenic potency of $\mathrm{AFB}_{1}$ for carriers $\left(\mathrm{P}_{\mathrm{HBsAg}+}=0.3\right.$ cancer $/$ year $/ 10^{5}$ individuals) and noncarriers $\left(\mathrm{P}_{\mathrm{HBsAg}-}=0.01\right.$ cancer $/$ year $/ 10^{5}$ individuals $)$.

$$
\text { Cancer risk }=\mathrm{P}_{\text {cancer }} \times \text { Exposure }(\mathrm{ng} / \mathrm{kg} \text { b.w. day })
$$

while

$$
\mathrm{P}_{\text {cancer }}=\left(\mathrm{P}_{\mathrm{HBsAg}+} \times \text { \%Pop.HBsAg }{ }^{+}\right)+\left(\mathrm{P}_{\mathrm{HBsAg}-} \times \% \text { Pop.HBsAg }{ }^{-}\right) .
$$

\subsection{Statistical Analysis}

The normality of the consumption data distribution and contamination data was assessed by Kolmogorov-Smirnov, Shapiro-Wilk test, and the corresponding Q/Q plots. A non-parametric 
Mann-Whitney $U$ test was applied to determine the significance, using the SPSS statistical package $\left(\right.$ IBM $^{\circledR}$, Version 14, SPSS Inc. Chicago, IL, USA, 2005) with a level of confidence of 0.05. All other calculations were executed in Excel 2010. The mean data together with standard deviations (SD) was stated. Significant differences in percentage degradation in $\mathrm{AFB}_{1}$ and $\mathrm{AFB}_{2}$ among various cooking processes were determined by Tukey's HSD test (IBM ${ }^{\circledR}$, Version 14, SPSS Inc. Chicago, IL, USA, 2005).

Acknowledgments: We thank the Higher Education Commission (HEC) of Pakistan for providing financial support to this study through awarding indigenous PhD scholarship to the first author (S.M.).

Author Contributions: S.M., M.D.B., and M.I. conceived and designed the experiments; S.M. performed the experiments; S.D.S., M.D.B., and W.R. analyzed the data; F.H., M.R., and A.T. contributed reagents/materials/analysis tools; S.M. and M.I. wrote the paper.

Conflicts of Interest: The authors declare no conflict of interest.

\section{Appendix A}

Table A1. Intraday repeatability (RSDr), interday repeatability (RSDR), apparent recovery (\%), and expanded measurement uncertainty $(\mathrm{U})$ of the individual mycotoxins for the rice matrix analyzed at spiked concentration levels, in triplicate on four different days.

\begin{tabular}{|c|c|c|c|c|c|}
\hline Mycotoxin & $\begin{array}{l}\text { Spike Conc. } \\
(\mu \mathrm{g} / \mathrm{kg})\end{array}$ & $\begin{array}{l}\mathrm{RSD}_{\mathrm{r}} \\
(\%)\end{array}$ & $\begin{array}{c}\mathrm{RSD}_{\mathrm{R}} \\
(\%)\end{array}$ & $\begin{array}{c}\text { Apparent } \\
\text { Recovery }(\%)\end{array}$ & $\begin{array}{c}\text { Expanded Measurement } \\
\text { Uncertainty U (\%)* }\end{array}$ \\
\hline \multirow{5}{*}{ ZEN } & 37.5 & 8 & 14 & 100 & 6 \\
\hline & 56.3 & 4 & 16 & 99 & 3 \\
\hline & 75 & 6 & 12 & 100 & 5 \\
\hline & 100 & 5 & 9 & 100 & 3 \\
\hline & 150 & 4 & 7 & 100 & 2 \\
\hline \multirow{5}{*}{ ENNB } & 100 & 14 & 20 & 80 & 17 \\
\hline & 150 & 12 & 17 & 86 & 17 \\
\hline & 200 & 9 & 17 & 111 & 13 \\
\hline & 300 & 12 & 14 & 96 & 24 \\
\hline & 400 & 10 & 12 & 99 & 22 \\
\hline \multirow{5}{*}{ ROQ-C } & 10 & 9 & 16 & 111 & 34 \\
\hline & 15 & 8 & 14 & 99 & 19 \\
\hline & 20 & 5 & 14 & 93 & 14 \\
\hline & 30 & 3 & 12 & 98 & 3 \\
\hline & 40 & 3 & 8 & 102 & 4 \\
\hline \multirow{5}{*}{ STREG } & 25 & 13 & 19 & 110 & 16 \\
\hline & 37.5 & 11 & 17 & 97 & 12 \\
\hline & 50 & 8 & 14 & 94 & 8 \\
\hline & 75 & 5 & 15 & 99 & 5 \\
\hline & 100 & 4 & 12 & 101 & 3 \\
\hline \multirow{5}{*}{ AME } & 100 & 11 & 12 & 102 & 9 \\
\hline & 150 & 9 & 12 & 99 & 4 \\
\hline & 200 & 6 & 11 & 99 & 3 \\
\hline & 300 & 7 & 10 & 99 & 3 \\
\hline & 400 & 5 & 9 & 100 & 3 \\
\hline \multirow{5}{*}{$\mathrm{FB}_{2}$} & 100 & 9 & 16 & 98 & 5 \\
\hline & 150 & 7 & 13 & 100 & 3 \\
\hline & 200 & 6 & 11 & 100 & 4 \\
\hline & 300 & 6 & 9 & 99 & 2 \\
\hline & 400 & 5 & 8 & 100 & 2 \\
\hline
\end{tabular}


Table A1. Cont.

\begin{tabular}{|c|c|c|c|c|c|}
\hline Mycotoxin & $\begin{array}{l}\text { Spike Conc. } \\
(\mu \mathrm{g} / \mathrm{kg})\end{array}$ & $\begin{array}{l}\operatorname{RSD}_{\mathrm{r}} \\
(\%)\end{array}$ & $\begin{array}{c}\mathrm{RSD}_{\mathrm{R}} \\
(\%)\end{array}$ & $\begin{array}{c}\text { Apparent } \\
\text { Recovery (\%) }\end{array}$ & $\begin{array}{c}\text { Expanded Measurement } \\
\text { Uncertainty U }(\%){ }^{*}\end{array}$ \\
\hline \multirow{5}{*}{ OTA } & 2.5 & 14 & 19 & 101 & 14 \\
\hline & 5 & 11 & 17 & 99 & 5 \\
\hline & 10 & 9 & 13 & 100 & 11 \\
\hline & 15 & 8 & 14 & 99 & 4 \\
\hline & 20 & 5 & 11 & 100 & 2 \\
\hline \multirow{5}{*}{$\mathrm{FB}_{3}$} & 125 & 7 & 16 & 99 & 3 \\
\hline & 187.5 & 8 & 14 & 99 & 3 \\
\hline & 250 & 6 & 11 & 100 & 4 \\
\hline & 375.5 & 5 & 8 & 99 & 3 \\
\hline & 500 & 4 & 7 & 99 & 3 \\
\hline \multirow{5}{*}{$\mathrm{T} 2$} & 50 & 13 & 18 & 106 & 30 \\
\hline & 75 & 10 & 15 & 96. & 17 \\
\hline & 100 & 11 & 14 & 99. & 9 \\
\hline & 150 & 11 & 14 & 99. & 7 \\
\hline & 200 & 9 & 13 & 100 & 6 \\
\hline \multirow{5}{*}{$\mathrm{FB}_{1}$} & 100 & 9 & 18 & 99 & 3 \\
\hline & 150 & 8 & 16 & 100 & 2 \\
\hline & 200 & 5 & 12 & 100 & 3 \\
\hline & 300 & 4 & 9 & 99 & 3 \\
\hline & 400 & 4 & 8 & 100 & 2 \\
\hline \multirow{5}{*}{ HT2 } & 50 & 14 & 20 & 105 & 26 \\
\hline & 75 & 13 & 19 & 98 & 19 \\
\hline & 100 & 9 & 17 & 97 & 7 \\
\hline & 150 & 6 & 13 & 100 & 3 \\
\hline & 200 & 3 & 12 & 100 & 4 \\
\hline \multirow{5}{*}{$\mathrm{AOH}$} & 50 & 9 & 19 & 101 & 18 \\
\hline & 75 & 9 & 17 & 99 & 17 \\
\hline & 100 & 7 & 15 & 98 & 16 \\
\hline & 150 & 6 & 11 & 101 & 14 \\
\hline & 200 & 3 & 8 & 99 & 9 \\
\hline \multirow{5}{*}{ DAS } & 10 & 7 & 16 & 98 & 21 \\
\hline & 15 & 5 & 15 & 102 & 17 \\
\hline & 20 & 6 & 11 & 99 & 11 \\
\hline & 30 & 6 & 9 & 99 & 8 \\
\hline & 40 & 4 & 7 & 100 & 4 \\
\hline \multirow{6}{*}{$\mathrm{AFB}_{1}$} & 2.5 & 8 & 15 & 95 & 16 \\
\hline & 5 & 7 & 13 & 100 & 16 \\
\hline & 7.5 & 7 & 11 & 96 & 11 \\
\hline & 10 & 5 & 9 & 100 & 9 \\
\hline & 15 & 4 & 7 & 102 & 7 \\
\hline & 20 & 4 & 7 & 98 & 4 \\
\hline \multirow{6}{*}{$\mathrm{AFB}_{2}$} & 2.5 & 7 & 17 & 96 & 14 \\
\hline & 5 & 7 & 15 & 100 & 12 \\
\hline & 7.5 & 5 & 13 & 97 & 11 \\
\hline & 10 & 5 & 12 & 101 & 5 \\
\hline & 15 & 4 & 9 & 100 & 3 \\
\hline & 20 & 3 & 7 & 99 & 4 \\
\hline
\end{tabular}


Table A1. Cont.

\begin{tabular}{|c|c|c|c|c|c|}
\hline Mycotoxin & $\begin{array}{l}\text { Spike Conc. } \\
(\mu \mathrm{g} / \mathrm{kg})\end{array}$ & $\begin{array}{l}\operatorname{RSD}_{\mathrm{r}} \\
(\%)\end{array}$ & $\begin{array}{c}\mathrm{RSD}_{\mathrm{R}} \\
(\%)\end{array}$ & $\begin{array}{c}\text { Apparent } \\
\text { Recovery (\%) }\end{array}$ & $\begin{array}{c}\text { Expanded Measurement } \\
\text { Uncertainty U (\%) }\end{array}$ \\
\hline \multirow{6}{*}{$\mathrm{AFG}_{1}$} & 2.5 & 7 & 18 & 98 & 13 \\
\hline & 5 & 6 & 18 & 101 & 12 \\
\hline & 7.5 & 5 & 15 & 99 & 11 \\
\hline & 10 & 4 & 12 & 101 & 7 \\
\hline & 15 & 3 & 9 & 98 & 7 \\
\hline & 20 & 3 & 6 & 100 & 5 \\
\hline \multirow{6}{*}{$\mathrm{AFG}_{2}$} & 2.5 & 8 & 16 & 97 & 14 \\
\hline & 5 & 7 & 15 & 101 & 13 \\
\hline & 7.5 & 6 & 13 & 99 & 11 \\
\hline & 10 & 5 & 13 & 100 & 7 \\
\hline & 15 & 5 & 8 & 99 & 5 \\
\hline & 20 & 4 & 7 & 100 & 4 \\
\hline \multirow{5}{*}{ 15-ADON } & 25 & 13 & 15 & 86 & 7 \\
\hline & 37.5 & 11 & 11 & 84 & 6 \\
\hline & 50 & 8 & 11 & 84 & 5 \\
\hline & 75 & 6 & 9 & 85 & 3 \\
\hline & 100 & 4 & 9 & 85 & 3 \\
\hline \multirow{5}{*}{ 3-ADON } & 50 & 12 & 20 & 102 & 9 \\
\hline & 75 & 11 & 16 & 99 & 7 \\
\hline & 100 & 9 & 16 & 98 & 6 \\
\hline & 150 & 6 & 14 & 100 & 3 \\
\hline & 200 & 5 & 11 & 100 & 2 \\
\hline \multirow{5}{*}{ FX } & 100 & 13 & 19 & 100 & 8 \\
\hline & 150 & 11 & 17 & 100 & 5 \\
\hline & 200 & 9 & 17 & 99 & 4 \\
\hline & 300 & 7 & 13 & 99 & 3 \\
\hline & 400 & 5 & 12 & 100 & 3 \\
\hline \multirow{5}{*}{ NEO } & 50 & 9 & 17 & 100 & 9 \\
\hline & 75 & 7 & 17 & 99 & 7 \\
\hline & 100 & 6 & 15 & 100 & 6 \\
\hline & 150 & 4 & 11 & 99 & 4 \\
\hline & 200 & 5 & 9 & 100 & 3 \\
\hline \multirow{5}{*}{$\mathrm{DON}$} & 100 & 7 & 15 & 102 & 8 \\
\hline & 150 & 8 & 13 & 99 & 6 \\
\hline & 200 & 6 & 10 & 99 & 5 \\
\hline & 300 & 5 & 9 & 100 & 4 \\
\hline & 400 & 3 & 6 & 100 & 3 \\
\hline \multirow{5}{*}{ NIV } & 50 & 7 & 16 & 99 & 5 \\
\hline & 75 & 6 & 14 & 99 & 4 \\
\hline & 100 & 7 & 13 & 100 & 3 \\
\hline & 150 & 5 & 11 & 99 & 3 \\
\hline & 200 & 4 & 8 & 100 & 3 \\
\hline
\end{tabular}

* With a maximum error limit of $20 \%$ and a $\beta$-tolerance interval of 0.85 . Abbreviation: ZEN = zearalenone; $\mathrm{ENNB}=$ Enniatin $\mathrm{B} ; \mathrm{ROQ}-\mathrm{C}=$ roquefortine- $\mathrm{C} ; \mathrm{STERIG}=$ sterigmatocystine; $\mathrm{AME}=$ alternariol methylether; $\mathrm{FB}_{1}$, $\mathrm{FB}_{2}$, and $\mathrm{FB}_{3}=$ fumonisin $\mathrm{B}_{1}, \mathrm{~B}_{2}$, and $\mathrm{B}_{3} ; \mathrm{OTA}=$ ochratoxin $\mathrm{A} ; \mathrm{T} 2=\mathrm{T}-2$ toxin; $\mathrm{HT} 2=\mathrm{HT}-2$ toxin; $\mathrm{AOH}=$ Alternariol; DAS = diacetoxyscirpenol; $\mathrm{AFB}_{1}, \mathrm{~B}_{2}, \mathrm{G}_{1}$, and $\mathrm{G}_{2}=$ aflatoxin $\mathrm{B}_{1}, \mathrm{~B}_{2}, \mathrm{G}_{1}$ and $\mathrm{G}_{2}$ : 15-ADON = 15-acetyl-deoxynivalenol; 3-ADON = 3-acetyl-deoxynivalenol; $\mathrm{F}-\mathrm{X}=$ fusarenon-X; $\mathrm{NEO}=$ neosolaniol; $\mathrm{DON}=$ deoxynivalenol; $\mathrm{NIV}=$ nivalenol. 


\section{Appendix B}

Survey Form: Food Frequency Questionnaires

Interview \#

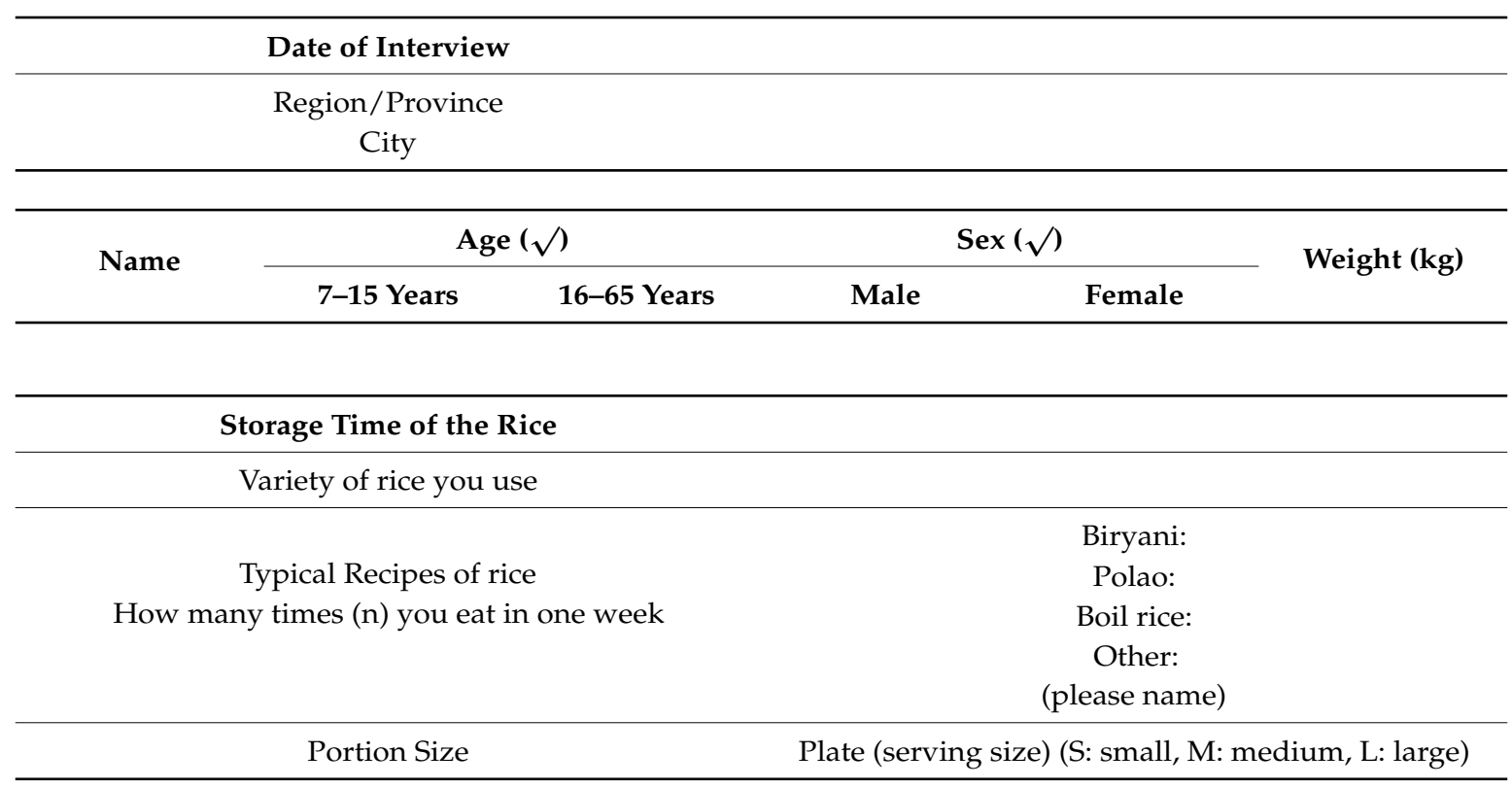

\begin{tabular}{|c|c|c|c|}
\hline \multicolumn{4}{|c|}{ Frequency of Rice Consumption during One Week } \\
\hline Serving Size $(\sqrt{ })$ and Number $(n)$ & Small & Medium & Large \\
\hline \multicolumn{4}{|l|}{ Monday } \\
\hline \multicolumn{4}{|l|}{ Breakfast } \\
\hline \multicolumn{4}{|l|}{ Lunch } \\
\hline \multicolumn{4}{|l|}{ Dinner } \\
\hline \multicolumn{4}{|l|}{ Tuesday } \\
\hline \multicolumn{4}{|l|}{ Breakfast } \\
\hline \multicolumn{4}{|l|}{ Lunch } \\
\hline \multicolumn{4}{|l|}{ Dinner } \\
\hline \multicolumn{4}{|l|}{ Wednesday } \\
\hline \multicolumn{4}{|l|}{ Breakfast } \\
\hline \multicolumn{4}{|l|}{ Lunch } \\
\hline \multicolumn{4}{|l|}{ Dinner } \\
\hline \multicolumn{4}{|l|}{ Thursday } \\
\hline \multicolumn{4}{|l|}{ Breakfast } \\
\hline \multicolumn{4}{|l|}{ Lunch } \\
\hline \multicolumn{4}{|l|}{ Dinner } \\
\hline \multicolumn{4}{|l|}{ Friday } \\
\hline \multicolumn{4}{|l|}{ Breakfast } \\
\hline \multicolumn{4}{|l|}{ Lunch } \\
\hline \multicolumn{4}{|l|}{ Dinner } \\
\hline \multicolumn{4}{|l|}{ Saturday } \\
\hline \multicolumn{4}{|l|}{ Breakfast } \\
\hline \multicolumn{4}{|l|}{ Lunch } \\
\hline \multicolumn{4}{|l|}{ Dinner } \\
\hline \multicolumn{4}{|l|}{ Sunday } \\
\hline \multicolumn{4}{|l|}{ Breakfast } \\
\hline \multicolumn{4}{|l|}{ Lunch } \\
\hline Dinner & & & \\
\hline
\end{tabular}




\section{Appendix C}

Table A2. Deterministic dietary exposures (ng/kg b.w./day) through the consumption of rice contaminated with multiple mycotoxins by the adult group of the population in North and South Punjab of Pakistan, using the upper bound scenario (<LOQ = LOQ). The calculations are based on (A) fixed mean mycotoxin concentration and variable rice consumption in the two regions and (B) fixed mean rice consumption and variable mycotoxins concentration in the two regions.

Values exceeding the PMTDI (provisional maximum tolerable daily intake) are shown in bold.

\begin{tabular}{|c|c|c|c|c|c|c|c|c|c|c|c|c|c|c|c|c|c|c|}
\hline \multirow{3}{*}{$\begin{array}{l}\text { Descriptive } \\
\text { Statistics }\end{array}$} & \multicolumn{16}{|c|}{ (A) Deterministic Exposure Analysis at Fixed Mycotoxin Concentration and Variable Rice Consumption. } & & \\
\hline & \multicolumn{2}{|c|}{$\mathrm{AFB}_{2}$} & \multicolumn{2}{|c|}{$\mathrm{AFB}_{1}$} & \multicolumn{2}{|c|}{ NIV } & \multicolumn{2}{|c|}{ DAS } & \multicolumn{2}{|c|}{$\mathrm{FB}_{1}$} & \multicolumn{2}{|c|}{ OTA } & \multicolumn{2}{|c|}{ DON } & \multicolumn{2}{|c|}{ HT2 } & \multicolumn{2}{|c|}{ ZEN } \\
\hline & SP & NP & SP & NP & SP & NP & SP & NP & SP & NP & SP & NP & SP & NP & SP & NP & SP & NP \\
\hline Mean & 1.22 & 1.83 & 4.47 & 7.31 & 25.1 & 42.3 & 3.84 & 5.35 & 34.1 & 61.9 & 1.17 & 1.93 & 10.8 & 17.0 & 8.51 & 12.9 & 17.2 & 26.7 \\
\hline Median & 1.16 & 1.71 & 4.23 & 6.83 & 23.7 & 39.5 & 3.63 & 5.01 & 32.3 & 57.9 & 1.11 & 1.80 & 10.2 & 15.9 & 8.05 & 12.1 & 16.3 & 24.9 \\
\hline Min. & 0.741 & 0.901 & 2.72 & 3.59 & 15.3 & 20.8 & 2.33 & 2.63 & 20.7 & 30.4 & 0.71 & 0.95 & 6.58 & 8.36 & 5.17 & 6.33 & 10.5 & 13.1 \\
\hline P75 & 1.37 & 2.10 & 5.02 & 8.37 & 28.2 & 48.4 & 4.31 & 6.13 & 38.3 & 70.9 & 1.31 & 2.21 & 12.2 & 19.5 & 9.55 & 14.8 & 19.3 & 30.6 \\
\hline P90 & 1.84 & 3.06 & 6.72 & 12.2 & 37.7 & 70.6 & 5.77 & 8.95 & 51.2 & 103 & 1.76 & 3.22 & 16.3 & 28.5 & 12.7 & 21.5 & 25.8 & 44.6 \\
\hline P95 & 1.98 & 3.14 & 7.23 & 12.5 & 40.6 & 72.4 & 6.21 & 9.18 & 55.1 & 106 & 1.89 & 3.31 & 17.5 & 29.2 & 13.7 & 22.1 & 27.8 & 45.8 \\
\hline Max. & 2.81 & 4.32 & 10.3 & 17.2 & 57.6 & 99.6 & 8.82 & 12.6 & 78.2 & 145 & 2.68 & 4.54 & 24.8 & 40.1 & 19.5 & 30.4 & 39.5 & 62.9 \\
\hline
\end{tabular}

(B) Deterministic Exposure Analysis at Fixed Rice Consumption and Variable Mycotoxin Concentration.

\begin{tabular}{|c|c|c|c|c|c|c|c|c|c|c|c|c|c|c|c|c|c|c|}
\hline \multirow{2}{*}{$\begin{array}{l}\text { Descriptive } \\
\text { Statistics }\end{array}$} & \multicolumn{2}{|c|}{$\mathrm{AFB}_{2}$} & \multicolumn{2}{|c|}{$\mathrm{AFB}_{1}$} & \multicolumn{2}{|c|}{ NIV } & \multicolumn{2}{|c|}{ DAS } & \multicolumn{2}{|c|}{$\mathrm{FB}_{1}$} & \multicolumn{2}{|c|}{ OTA } & \multicolumn{2}{|c|}{ DON } & \multicolumn{2}{|c|}{ HT2 } & \multicolumn{2}{|c|}{ ZEN } \\
\hline & SP & NP & SP & NP & SP & NP & SP & NP & SP & NP & SP & NP & SP & NP & SP & NP & SP & NP \\
\hline Mean & 1.22 & 1.83 & 4.47 & 7.31 & 25.1 & 42.2 & 3.84 & 5.35 & 34.1 & 61.9 & 1.17 & 1.93 & 10.82 & 17.03 & 8.51 & 12.9 & 17.2 & 26.7 \\
\hline Median & 0.920 & 1.61 & 4.07 & 5.40 & $<$ LOD & $<\mathrm{LOD}$ & $<\mathrm{LOD}$ & $<\mathrm{LOD}$ & $<\mathrm{LOD}$ & 28.3 & $<\mathrm{LOD}$ & $<\mathrm{LOD}$ & $<$ LOD & $<$ LOD & $<\mathrm{LOD}$ & $<\mathrm{LOD}$ & $<\mathrm{LOD}$ & $<\mathrm{LOD}$ \\
\hline Min. & $<$ LOD & $<\mathrm{LOD}$ & $<$ LOD & $<\mathrm{LOD}$ & $<$ LOD & $<\mathrm{LOD}$ & $<$ LOD & $<$ LOD & $<\mathrm{LOD}$ & $<\mathrm{LOD}$ & $<\mathrm{LOD}$ & $<$ LOD & $<$ LOD & $<$ LOD & $<$ LOD & $<\mathrm{LOD}$ & $<\mathrm{LOD}$ & $<\mathrm{LOD}$ \\
\hline P75 & 1.71 & 2.90 & 5.86 & 10.4 & 26.5 & 39.3 & 9.96 & 13.1 & 96.6 & 127 & $<\mathrm{LOD}$ & $<\mathrm{LOD}$ & $<\mathrm{LOD}$ & $<\mathrm{LOD}$ & $<\mathrm{LOD}$ & $<\mathrm{LOD}$ & 21.6 & 28.4 \\
\hline P90 & 3.19 & 4.38 & 12.9 & 16.3 & 90.2 & 133 & 11.2 & 14.8 & 96.6 & 138 & 4.15 & 5.46 & $<\mathrm{LOD}$ & $<\mathrm{LOD}$ & 43.2 & 56.7 & 78.3 & 104 \\
\hline P95 & 5.04 & 6.69 & 14.2 & 19.0 & 124.3 & 192 & 11.3 & 14.8 & 103 & 144 & 6.76 & 15.1 & 124 & 168 & 43.2 & 58.7 & 79.5 & 111 \\
\hline Max. & 5.16 & 7.39 & 16.5 & 42.7 & 177 & 254 & 20.7 & 16.4 & 105 & 163 & 18.3 & 52.3 & 127 & 250 & 51.5 & 69.8 & 190 & 250 \\
\hline
\end{tabular}

PMTDI values (ng/kg b.w. day): $\mathrm{AFB}_{1}=0.0001, \mathrm{AFB}_{2}=0.0001, \mathrm{NIV}=700, \mathrm{DAS}=100, \mathrm{FB}_{1}=2000, \mathrm{OTA}=17, \mathrm{DON}=1000, \mathrm{HT2}=100, \mathrm{ZEN}=250$. 


\section{Appendix D}

Table A3. Deterministic dietary exposures (ng/kg b.w./day) through the consumption of rice contaminated with multiple mycotoxins by children in North and South Punjab of Pakistan, using the upper bound scenario ( $<\mathrm{LOQ}=\mathrm{LOQ})$. The calculations are based on (A) fixed mean mycotoxin concentration and variable rice consumption in the two regions and (B) fixed mean rice consumption and variable mycotoxins concentration in the two regions. Values exceeding the PMTDI (provisional maximum tolerable daily intake) are shown in bold.

\begin{tabular}{|c|c|c|c|c|c|c|c|c|c|c|c|c|c|c|c|c|c|c|}
\hline \multirow{3}{*}{$\begin{array}{l}\text { Descriptive } \\
\text { Statistics }\end{array}$} & \multicolumn{16}{|c|}{ (A) Deterministic Exposure Analysis at Fixed Mycotoxin Concentration and Variable Rice Consumption. } & & \\
\hline & \multicolumn{2}{|c|}{$\mathrm{AFB}_{2}$} & \multicolumn{2}{|c|}{$\mathrm{AFB}_{1}$} & \multicolumn{2}{|c|}{ NIV } & \multicolumn{2}{|c|}{ DAS } & \multicolumn{2}{|c|}{$\mathrm{FB}_{1}$} & \multicolumn{2}{|c|}{ OTA } & \multicolumn{2}{|c|}{ DON } & \multicolumn{2}{|c|}{ HT2 } & \multicolumn{2}{|c|}{ ZEN } \\
\hline & SP & NP & SP & NP & SP & NP & SP & NP & SP & NP & SP & NP & SP & NP & SP & NP & SP & NP \\
\hline Mean & 1.24 & 1.90 & 4.53 & 7.58 & 25.4 & 43.8 & 3.89 & 5.55 & 34.5 & 64.2 & 1.18 & 2.00 & 10.9 & 17.6 & 8.61 & 13.4 & 17.4 & 27.7 \\
\hline Median & 1.13 & 1.80 & 4.13 & 7.17 & 23.2 & 41.5 & 3.54 & 5.26 & 31.4 & 60.7 & 1.08 & 1.89 & 9.98 & 16.7 & 7.85 & 12.7 & 15.8 & 26.2 \\
\hline Min. & 0.820 & 1.03 & 2.99 & 4.10 & 16.7 & 23.7 & 2.57 & 3.00 & 22.7 & 34.7 & 0.780 & 1.08 & 7.23 & 9.56 & 5.68 & 7.24 & 11.5 & 14.9 \\
\hline P75 & 1.32 & 2.25 & 4.81 & 8.97 & 27.0 & 51.8 & 4.13 & 6.57 & 36.6 & 75.9 & 1.26 & 2.37 & 11.6 & 20.9 & 9.15 & 15.8 & 18.5 & 32.7 \\
\hline P90 & 1.58 & 2.70 & 5.78 & 10.7 & 32.4 & 62.2 & 4.96 & 7.88 & 44.0 & 91.1 & 1.51 & 2.84 & 13.9 & 25.1 & 10.9 & 18.9 & 22.2 & 39.3 \\
\hline P95 & 2.11 & 3.00 & 7.70 & 11.9 & 43.2 & 69.1 & 6.61 & 8.76 & 58.6 & 101.3 & 2.01 & 3.16 & 18.6 & 27.8 & 14.6 & 21.1 & 29.6 & 43.7 \\
\hline Max. & 3.16 & 4.09 & 11.5 & 16.3 & 64.9 & 94.3 & 9.92 & 11.9 & 88.0 & 138 & 3.02 & 4.30 & 27.9 & 38.0 & 21.9 & 28.7 & 44.5 & 59.6 \\
\hline
\end{tabular}

(B) Deterministic Exposure Analysis at Fixed Rice Consumption and Variable Mycotoxin Concentration.

\begin{tabular}{|c|c|c|c|c|c|c|c|c|c|c|c|c|c|c|c|c|c|c|}
\hline \multirow{2}{*}{$\begin{array}{l}\text { Descriptive } \\
\text { Statistics }\end{array}$} & \multicolumn{2}{|c|}{$\mathrm{AFB}_{2}$} & \multicolumn{2}{|c|}{$\mathrm{AFB}_{1}$} & \multicolumn{2}{|c|}{ NIV } & \multicolumn{2}{|c|}{ DAS } & \multicolumn{2}{|c|}{$\mathrm{FB}_{1}$} & \multicolumn{2}{|c|}{ OTA } & \multicolumn{2}{|c|}{ DON } & \multicolumn{2}{|c|}{ HT2 } & \multicolumn{2}{|c|}{ ZEN } \\
\hline & SP & NP & SP & NP & SP & NP & SP & NP & SP & NP & SP & NP & SP & NP & SP & NP & SP & $\mathbf{N P}$ \\
\hline Mean & 1.24 & 1.90 & 4.53 & 7.58 & 25.4 & 43.8 & 3.89 & 5.55 & 34.5 & 64.2 & 1.18 & 2.00 & 10.9 & 17.6 & 8.61 & 13.4 & 17.4 & 27.7 \\
\hline Median & 0.930 & 1.67 & 4.11 & 5.60 & $<\mathrm{LOD}$ & $<\mathrm{LOD}$ & $<\mathrm{LOD}$ & $<\mathrm{LOD}$ & $<\mathrm{LOD}$ & 29.4 & $<\mathrm{LOD}$ & $<\mathrm{LOD}$ & $<\mathrm{LOD}$ & $<$ LOD & $<\mathrm{LOD}$ & $<\mathrm{LOD}$ & $<\mathrm{LOD}$ & $<\mathrm{LOD}$ \\
\hline Min. & $<\mathrm{LOD}$ & $<\mathrm{LOD}$ & $<\mathrm{LOD}$ & $<\mathrm{LOD}$ & $<\mathrm{LOD}$ & $<\mathrm{LOD}$ & $<\mathrm{LOD}$ & $<\mathrm{LOD}$ & $<\mathrm{LOD}$ & $<\mathrm{LOD}$ & $<\mathrm{LOD}$ & $<\mathrm{LOD}$ & $<\mathrm{LOD}$ & $<\mathrm{LOD}$ & $<\mathrm{LOD}$ & $<\mathrm{LOD}$ & $<\mathrm{LOD}$ & $<\mathrm{LOD}$ \\
\hline P75 & 1.73 & 3.00 & 5.93 & 10.8 & 26.8 & 40.7 & 10.1 & 13.6 & 97.8 & 131 & $<\mathrm{LOD}$ & $<\mathrm{LOD}$ & $<\mathrm{LOD}$ & $<\mathrm{LOD}$ & $<\mathrm{LOD}$ & $<\mathrm{LOD}$ & 21.83 & 29.42 \\
\hline P90 & 3.23 & 4.54 & 13.1 & 16.9 & 91.2 & 138 & 11.4 & 15.3 & 97.8 & 143 & 4.20 & 5.66 & 0.00 & 0.00 & 43.6 & 58.8 & 79.2 & 108 \\
\hline P95 & 5.10 & 6.94 & 14.4 & 19.7 & 125 & 199 & 11.5 & 15.4 & 105 & 149 & 6.84 & 15.6 & 125 & 174 & 43.6 & 60.8 & 80.4 & 116 \\
\hline Max. & 5.22 & 7.66 & 16.8 & 44.4 & 179 & 264 & 21.0 & 17.0 & 106 & 170 & 18.5 & 54.3 & 129 & 260 & 52.1 & 72.4 & 192 & 259 \\
\hline
\end{tabular}

PMTDI values (ng/kg b.w. day): $\mathrm{AFB}_{1}=0.0001, \mathrm{AFB}_{2}=0.0001, \mathrm{NIV}=700, \mathrm{DAS}=100, \mathrm{FB}_{1}=2000, \mathrm{OTA}=17, \mathrm{DON}=1000, \mathrm{HT} 2=100, \mathrm{ZEN}=250$. 


\section{Appendix E}

Table A4. Deterministic dietary exposures (ng/kg b.w./day) through the consumption of rice contaminated with multiple mycotoxins by the adult group of the population in North and South Punjab of Pakistan, using the lower bound scenario $(<\mathrm{LOQ}=0)$. The calculations are based on $(\mathbf{A})$ fixed mean mycotoxin concentration and variable rice consumption in the two regions and (B) fixed mean rice consumption and variable mycotoxins concentration in the two regions. Values exceeding the PMTDI (provisional maximum tolerable daily intake) are shown in bold.

\begin{tabular}{|c|c|c|c|c|c|c|c|c|c|c|c|c|c|c|c|c|c|c|}
\hline \multirow{3}{*}{$\begin{array}{l}\text { Descriptive } \\
\text { Statistics }\end{array}$} & \multicolumn{16}{|c|}{ (A) Deterministic Exposure Analysis at Fixed Mycotoxin Concentration and Variable Rice Consumption. } & & \\
\hline & \multicolumn{2}{|c|}{$\mathrm{AFB}_{2}$} & \multicolumn{2}{|c|}{$\mathbf{A F B}_{1}$} & \multicolumn{2}{|c|}{ NIV } & \multicolumn{2}{|c|}{ DAS } & \multicolumn{2}{|c|}{$\mathbf{F B}_{1}$} & \multicolumn{2}{|c|}{ OTA } & \multicolumn{2}{|c|}{ DON } & \multicolumn{2}{|c|}{ HT2 } & \multicolumn{2}{|c|}{ ZEN } \\
\hline & SP & NP & SP & NP & SP & NP & SP & NP & SP & NP & SP & NP & SP & NP & SP & NP & SP & NP \\
\hline Mean & 1.04 & 1.73 & 4.07 & 7.17 & 18.6 & 35.8 & 2.57 & 3.62 & 30.9 & 59.4 & 0.821 & 1.57 & 10.8 & 16.1 & 2.08 & 6.11 & 13.2 & 20.5 \\
\hline Median & 0.980 & 1.62 & 3.86 & 6.70 & 17.6 & 33.5 & 2.43 & 3.39 & 29.2 & 55.5 & 0.770 & 1.47 & 10.2 & 15.1 & 1.97 & 5.72 & 12.5 & 19.2 \\
\hline Min. & 0.631 & 0.850 & 2.48 & 3.52 & 11.3 & 17.6 & 1.56 & 1.78 & 18.8 & 29.2 & 0.500 & 0.77 & 6.58 & 7.93 & 1.26 & 3.00 & 8.04 & 10.1 \\
\hline P75 & 1.17 & 1.98 & 4.58 & 8.21 & 20.9 & 41.0 & 2.89 & 4.15 & 34.7 & 68.0 & 0.92 & 1.80 & 12.1 & 18.5 & 2.34 & 7.00 & 14.8 & 23.5 \\
\hline P90 & 1.56 & 2.89 & 6.12 & 11.9 & 27.9 & 59.8 & 3.86 & 6.05 & 46.4 & 99.2 & 1.23 & 2.63 & 16.2 & 27.0 & 3.13 & 10.2 & 19.8 & 34.3 \\
\hline P95 & 1.68 & 2.96 & 6.59 & 12.2 & 30.1 & 61.4 & 4.16 & 6.21 & 49.9 & 101 & 1.32 & 2.70 & 17.5 & 27.7 & 3.37 & 10.5 & 21.4 & 35.2 \\
\hline Max. & 2.39 & 4.07 & 9.35 & 16.8 & 42.7 & 84.4 & 5.90 & 8.54 & 70.9 & 140 & 1.87 & 3.71 & 24.8 & 38.1 & 4.78 & 14.4 & 30.4 & 48.4 \\
\hline \multicolumn{19}{|c|}{ (B) Deterministic Exposure Analysis at Fixed Rice Consumption and Variable Mycotoxin Concentration. } \\
\hline \multirow{2}{*}{$\begin{array}{l}\text { Descriptive } \\
\text { Statistics }\end{array}$} & \multicolumn{2}{|c|}{$\mathrm{AFB}_{2}$} & \multicolumn{2}{|c|}{$\mathrm{AFB}_{1}$} & \multicolumn{2}{|c|}{ NIV } & \multicolumn{2}{|c|}{ DAS } & \multicolumn{2}{|c|}{$\mathbf{F B}_{1}$} & \multicolumn{2}{|c|}{ OTA } & \multicolumn{2}{|c|}{ DON } & \multicolumn{2}{|c|}{ HT2 } & \multicolumn{2}{|c|}{ ZEN } \\
\hline & SP & $\mathrm{NP}$ & SP & NP & SP & NP & SP & NP & SP & NP & SP & NP & SP & NP & SP & NP & SP & NP \\
\hline Mean & 1.04 & 1.73 & 4.07 & 7.17 & 18.6 & 35.8 & 2.57 & 3.62 & 30.8 & 59.3 & 0.821 & 1.57 & 10.8 & 16.2 & 2.08 & 6.11 & 13.2 & 20.5 \\
\hline Median & $<\mathrm{LOD}$ & 1.61 & 4.07 & 5.40 & $<\mathrm{LOD}$ & $<\mathrm{LOD}$ & $<\mathrm{LOD}$ & $<$ LOD & $<$ LOD & $<\mathrm{LOD}$ & $<\mathrm{LOD}$ & $<\mathrm{LOD}$ & $<\mathrm{LOD}$ & $<\mathrm{LOD}$ & $<\mathrm{LOD}$ & $<\mathrm{LOD}$ & $<\mathrm{LOD}$ & $<\mathrm{LOD}$ \\
\hline Min. & $<\mathrm{LOD}$ & $<\mathrm{LOD}$ & $<\mathrm{LOD}$ & $<\mathrm{LOD}$ & $<\mathrm{LOD}$ & $<\mathrm{LOD}$ & $<\mathrm{LOD}$ & $<\mathrm{LOD}$ & $<\mathrm{LOD}$ & $<\mathrm{LOD}$ & $<\mathrm{LOD}$ & $<\mathrm{LOD}$ & $<\mathrm{LOD}$ & $<\mathrm{LOD}$ & $<\mathrm{LOD}$ & $<\mathrm{LOD}$ & $<\mathrm{LOD}$ & $<\mathrm{LOD}$ \\
\hline P75 & 1.71 & 2.90 & 5.86 & 10.4 & 0.00 & 39.28 & $<\mathrm{LOD}$ & $<$ LOD & 96.6 & 127 & $<\mathrm{LOD}$ & $<\mathrm{LOD}$ & $<\mathrm{LOD}$ & $<\mathrm{LOD}$ & $<\mathrm{LOD}$ & $<\mathrm{LOD}$ & $<\mathrm{LOD}$ & $<\mathrm{LOD}$ \\
\hline P90 & 2.66 & 4.38 & 10.9 & 16.3 & 90.2 & 133 & 11.3 & 14.8 & 96.6 & 138 & $<\mathrm{LOD}$ & $<\mathrm{LOD}$ & $<\mathrm{LOD}$ & $<\mathrm{LOD}$ & $<\mathrm{LOD}$ & 29.5 & 78.3 & 104 \\
\hline P95 & 4.39 & 6.69 & 13.3 & 19.0 & 124 & 192 & 11.3 & 14.8 & 104 & 144 & 4.07 & 15.1 & 124 & 168 & $<\mathrm{LOD}$ & 58.7 & 79.5 & 111 \\
\hline Max. & 5.16 & 7.39 & 14.6 & 42.7 & 177 & 255 & 20.7 & 16.4 & 105 & 164 & 18.3 & 52.4 & 128 & 250 & 51.5 & 69.8 & 190 & 250 \\
\hline
\end{tabular}

PMTDI values (ng/kg b.w. day): $\mathrm{AFB}_{1}=0.0001, \mathrm{AFB}_{2}=0.0001, \mathrm{NIV}=700, \mathrm{DAS}=100, \mathrm{FB}_{1}=2000, \mathrm{OTA}=17, \mathrm{DON}=1000, \mathrm{HT} 2=100, \mathrm{ZEN}=250$. 


\section{Appendix F}

Table A5. Deterministic dietary exposures (ng/kg b.w./day) through the consumption of rice contaminated with multiple mycotoxins by children in North and South Punjab of Pakistan, using the lower bound scenario $(<\mathrm{LOQ}=0)$. The calculations are based on $(\mathrm{A})$ fixed mean mycotoxin concentration and variable rice consumption in the two regions and (B) fixed mean rice consumption and variable mycotoxins concentration in the two regions. Values exceeding the PMTDI (provisional maximum tolerable daily intake) are shown in bold.

\begin{tabular}{|c|c|c|c|c|c|c|c|c|c|c|c|c|c|c|c|c|c|c|}
\hline \multirow{3}{*}{$\begin{array}{l}\text { Descriptive } \\
\text { Statistics }\end{array}$} & \multicolumn{16}{|c|}{ (A) Deterministic Exposure Analysis at Fixed Mycotoxin Concentration and Variable Rice Consumption. } & & \\
\hline & \multicolumn{2}{|c|}{$\mathrm{AFB}_{2}$} & \multicolumn{2}{|c|}{$\mathbf{A F B}_{1}$} & \multicolumn{2}{|c|}{ NIV } & \multicolumn{2}{|c|}{ DAS } & \multicolumn{2}{|c|}{$\mathbf{F B}_{1}$} & \multicolumn{2}{|c|}{ OTA } & \multicolumn{2}{|c|}{ DON } & \multicolumn{2}{|c|}{ HT2 } & \multicolumn{2}{|c|}{ ZEN } \\
\hline & SP & NP & SP & NP & SP & NP & SP & NP & SP & NP & SP & NP & SP & NP & SP & NP & SP & NP \\
\hline Mean & 1.05 & 1.79 & 4.12 & 7.43 & 18.8 & 37.1 & 2.60 & 3.76 & 31.2 & 61.6 & 0.83 & 1.63 & 10.9 & 16.8 & 2.11 & 6.34 & 13.4 & 21.3 \\
\hline Median & 0.960 & 1.70 & 3.76 & 7.04 & 17.2 & 35.1 & 2.37 & 3.56 & 28.4 & 58.3 & 0.75 & 1.54 & 9.98 & 15.8 & 1.92 & 6.00 & 12.2 & 20.2 \\
\hline Min. & 0.690 & 0.971 & 2.72 & 4.02 & 12.4 & 20.1 & 1.72 & 2.03 & 20.6 & 33.3 & 0.54 & 0.88 & 7.23 & 9.06 & 1.39 & 3.43 & 8.83 & 11.5 \\
\hline P75 & 1.12 & 2.12 & 4.38 & 8.80 & 20.0 & 43.9 & 2.77 & 4.45 & 33.2 & 72.8 & 0.88 & 1.93 & 11.6 & 19.8 & 2.24 & 7.50 & 14.2 & 25.2 \\
\hline P90 & 1.34 & 2.54 & 5.26 & 10.5 & 24.0 & 52.7 & 3.32 & 5.33 & 39.8 & 87.5 & 1.05 & 2.32 & 13.9 & 23.8 & 2.69 & 9.00 & 17.0 & 30.3 \\
\hline P95 & 1.79 & 2.83 & 7.02 & 11.7 & 32.1 & 58.6 & 4.42 & 5.93 & 53.1 & 97.2 & 1.40 & 2.57 & 18.6 & 26.4 & 3.58 & 10.0 & 22.7 & 33.63 \\
\hline Max. & 2.69 & 3.85 & 10.52 & 15.9 & 48.1 & 79.9 & 6.64 & 8.08 & 79.7 & 132 & 2.11 & 3.51 & 27.9 & 36.1 & 5.37 & 13.6 & 34.2 & 45.8 \\
\hline \multicolumn{19}{|c|}{ (B) Deterministic Exposure Analysis at Fixed Rice Consumption and Variable Mycotoxin Concentration. } \\
\hline \multirow{2}{*}{$\begin{array}{l}\text { Descriptive } \\
\text { Statistics }\end{array}$} & \multicolumn{2}{|c|}{$\mathrm{AFB}_{2}$} & \multicolumn{2}{|c|}{$\mathrm{AFB}_{1}$} & \multicolumn{2}{|c|}{ NIV } & \multicolumn{2}{|c|}{ DAS } & \multicolumn{2}{|c|}{$\mathrm{FB}_{1}$} & \multicolumn{2}{|c|}{ OTA } & \multicolumn{2}{|c|}{ DON } & \multicolumn{2}{|c|}{ HT2 } & \multicolumn{2}{|c|}{ ZEN } \\
\hline & SP & $\mathrm{NP}$ & SP & NP & SP & NP & SP & NP & SP & NP & SP & NP & SP & NP & SP & NP & SP & NP \\
\hline Mean & 1.05 & 1.79 & 4.12 & 7.43 & 18.8 & 37.1 & 2.60 & 3.76 & 31.2 & 61.6 & 0.831 & 1.63 & 10.9 & 16.7 & 2.11 & 6.34 & 13.4 & 21.3 \\
\hline Median & $<\mathrm{LOD}$ & 1.67 & 4.11 & 5.60 & $<\mathrm{LOD}$ & $<\mathrm{LOD}$ & $<\mathrm{LOD}$ & $<$ LOD & $<\mathrm{LOD}$ & $<\mathrm{LOD}$ & $<\mathrm{LOD}$ & $<\mathrm{LOD}$ & $<\mathrm{LOD}$ & $<\mathrm{LOD}$ & $<\mathrm{LOD}$ & $<\mathrm{LOD}$ & $<\mathrm{LOD}$ & $<\mathrm{LOD}$ \\
\hline Min. & $<\mathrm{LOD}$ & $<\mathrm{LOD}$ & $<\mathrm{LOD}$ & $<\mathrm{LOD}$ & $<\mathrm{LOD}$ & $<\mathrm{LOD}$ & $<\mathrm{LOD}$ & $<\mathrm{LOD}$ & $<\mathrm{LOD}$ & $<\mathrm{LOD}$ & $<\mathrm{LOD}$ & $<\mathrm{LOD}$ & $<\mathrm{LOD}$ & $<\mathrm{LOD}$ & $<\mathrm{LOD}$ & $<\mathrm{LOD}$ & $<\mathrm{LOD}$ & $<\mathrm{LOD}$ \\
\hline P75 & 1.73 & 3.00 & 5.93 & 10.8 & $<\mathrm{LOD}$ & 40.7 & $<\mathrm{LOD}$ & 3.45 & 97.8 & 131 & $<\mathrm{LOD}$ & $<\mathrm{LOD}$ & $<\mathrm{LOD}$ & $<$ LOD & $<\mathrm{LOD}$ & $<\mathrm{LOD}$ & $<\mathrm{LOD}$ & $<\mathrm{LOD}$ \\
\hline P90 & 2.70 & 4.54 & 11.1 & 16.9 & 91.3 & 138 & 11.4 & 15.4 & 97.8 & 143 & $<\mathrm{LOD}$ & $<\mathrm{LOD}$ & $<\mathrm{LOD}$ & $<\mathrm{LOD}$ & $<\mathrm{LOD}$ & 30.5 & 79.3 & 108 \\
\hline P95 & 4.44 & 6.94 & 13.5 & 19.7 & 125 & 199 & 11.5 & 15.4 & 105 & 149 & 4.11 & 15.62 & 125 & 174 & $<\mathrm{LOD}$ & 60.8 & 80.4 & 116 \\
\hline Max. & 5.22 & 7.66 & 14.8 & 44.4 & 179 & 264 & 21.0 & 17.0 & 106 & 170 & 18.5 & 54.3 & 129 & 260 & 52.1 & 72.4 & 192 & 259 \\
\hline
\end{tabular}

PMTDI values (ng $/ \mathrm{kg}$ b.w. day): $\mathrm{AFB}_{1}=0.0001, \mathrm{AFB}_{2}=0.0001, \mathrm{NIV}=700, \mathrm{DAS}=100, \mathrm{FB}_{1}=2000, \mathrm{OTA}=17, \mathrm{DON}=1000, \mathrm{HT2}=100, \mathrm{ZEN}=250$. 


\section{References}

1. Marin, S.; Ramos, A.; Cano-Sancho, G.; Sanchis, V. Mycotoxins: Occurrence, toxicology, and exposure assessment. Food Chem. Toxicol. 2013, 60, 218-237. [CrossRef] [PubMed]

2. Awika, J.M. Major Cereal Grains Production and Use around the World. In Advances in Cereal Science: Implications to Food Processing and Health Promotion; American Chemical Society: Washington, DC, USA, 2011; Volume 1089, pp. 1-13. [CrossRef]

3. United States Department of Agriculture (USDA). Production, Supply, \& Distribution Online Data Base, Foreign Agricultural Service. 2017. Available online: https:/ / www.fas.usda.gov/data (accessed on 22 April 2017).

4. Reddy, K.R.; Reddy, C.S.; Muralidharan, K. Detection of Aspergillus spp. and aflatoxin $\mathrm{B}_{1}$ in rice in India. Food Microbiol. 2009, 26, 27-31. [CrossRef] [PubMed]

5. Saleemullah; Iqbal, A.; Khalil, I.A.; Shah, H. Aflatoxin contents of stored and artificially inoculated cereals and nuts. Food Chem. 2006, 98, 699-703. [CrossRef]

6. De Ruyck, K.; De Boevre, M.; Huybrechts, I.; De Saeger, S. Dietary mycotoxins, co-exposure, and carcinogenesis in humans: Short review. Mutat. Res. Rev. Mutat. Res. 2015, 766, 32-41. [CrossRef] [PubMed]

7. Murphy, P.A.; Hendrich, S.; Landgren, C.; Bryant, C.M. Food mycotoxins: An update. J. Food Sci. 2006, 71, R51-R65. [CrossRef]

8. El-Serag, H.B.; Rudolph, K.L. Hepatocellular carcinoma: Epidemiology and molecular carcinogenesis. Gastroenterology 2007, 132, 2557-2576. [CrossRef] [PubMed]

9. International Agency for Research on Cancer. Monographs on the Evaluation of the Carcinogenic Risks to Humans: Some Naturally Occurring Substances: Food Items and Constituents, Heterocyclic Aromatic Amines and Mycotoxins; IARC Press: Lyon, France, 1993; Volume 56.

10. International Agency for Research on Cancer. Monographs on the Evaluation of the Carcinogenic Risks to Humans: Some Traditional Herbal Medicines, Some Mycotoxins, Naphthalene and Styrene; IARC Press: Lyon, France, 2002; Volume 82.

11. European Community (EC). Consolidated Version of the Commission Regulations on Setting Maximum Levels of Mycotoxins. Available online: http:/ / eur-lex.europa.eu/legal-content/EN/TXT/?uri=CELEX: 02006R1881-20170728 (accessed on 6 January 2018).

12. European Community (EC). Commission Regulation No 165/2013 of 17 March 2013 on the Presence of T-2 and HT-2 Toxin in Cereals and Cereal Products. 2013. Available online: http://eurlex.europa.eu/legalcontent/AUTO/?uri=CELEX:32013H0165\&qid=1517149641210\&rid=1 (accessed on 6 January 2018).

13. Borchers, A.; Teuber, S.S.; Keen, C.L.; Gershwin, M.E. Food safety. Clin. Rev. Allergy Immunol. 2010, 39, 95-141. [CrossRef] [PubMed]

14. Richard, J.L. Some major mycotoxins and their mycotoxicoses-An overview. Int. J. Food Microbiol. 2007, 119, 3-10. [CrossRef] [PubMed]

15. FAO/WHO. Food Safety Risk Analysis. In A Guide for National Food Safety Authoritue; FAO Food and Nutrition Paper; FAO: Rome, Italy, 2006; Volume 87. Available online: http:/ / www.fao.org/docrep/012/ a0822e/a0822e.pdf (accessed on 6 May 2017).

16. Joint FAO/WHO Expert Committee on Food Additives (JECFA). Summary and Conclusions. In Proceedings of the Seventy-Second Meeting, Rome, Italy, 16-25 February 2010.

17. European Food safety Authority (EFSA). Scientific Opinion on risks for animal and public health related to the presence of nivalenol in food and feed. EFSA J. 2013, 11, 3262. [CrossRef]

18. European Food safety Authority (EFSA). Scientific Opinion on risks for animal and public health related to the presence of T-2 and HT-2 toxin in food and feed. EFSA J. 2011, 9, 2481. [CrossRef]

19. European Food Safety Authority (EFSA). Scientific Opinion on the risks for public health related to the presence of zearalenone in food. EFSA J. 2011, 9, 2197. [CrossRef]

20. Food and Agriculture Organization of the United Nations (FAO); World Health Organization (WHO). Safety Evaluation of Certain food Additives and Contaminants; Fumonisins, WHO Food Additives Series; FAO: Rome, Italy; WHO: Geneva, Switzerland, 2012; Volume 65, pp. 325-794.

21. European Food safety Authority (EFSA). Opinion of the Scientific Panel on Contaminants in the Food Chain Related. Statement on Recent Scientific Information on the Toxicity of Ochratoxin A; EFSA: Parma, Italy, 2010. 
22. Joint FAO/WHO Expert Committee on Food Additives (JECFA). Safety Evaluation of Certain Food Additives and Contaminants, WHO Food Additive Series, Aflatoxins. In Proceedings of the Forty-Ninth Meeting of the Joint FAO/WHO Expert Committee on Food Additives, Geneva, Switzerland, 17-26 June 1997; Volume 40.

23. European Food Safety Authority (EFSA). Opinion of scientific committee on request from related to a harmonised approach for risk assessment of substance which are both genotoxic and carcinogenic (Request No EFSA-Q-2004-020), Adopted: 18 October 2005. EFSA J. 2005, 282, 1-31.

24. Firdous, S.; Ejaz, N.; Aman, T.; Khan, N. Occurrence of aflatoxins in export-quality Pakistani rice. Food Addit. Contam. B Surveill. 2012, 5, 121-125. [CrossRef] [PubMed]

25. Iqbal, S.Z.; Asi, M.R.; Arino, A.; Akram, N.; Zuber, M. Aflatoxin contamination in different fractions of rice from Pakistan and estimation of dietary intakes. Mycotoxin Res. 2012, 28, 175-180. [CrossRef] [PubMed]

26. Iqbal, S.Z.; Asi, M.R.; Hanif, U.; Zuber, M.; Jinap, S. The presence of aflatoxins and ochratoxin a in rice and rice products; and evaluation of dietary intake. Food Chem. 2016, 210, 135-140. [CrossRef] [PubMed]

27. Iqbal, S.Z.; Mustafa, H.G.; Asi, M.R.; Jinap, S. Variation in vitamin E level and aflatoxins contamination in different rice varieties. J. Cereal Sci. 2014, 60, 352-355. [CrossRef]

28. Lutfullah, G.; Hussain, A. Studies on contamination level of aflatoxins in some cereals and beans of Pakistan. Food Control 2012, 23, 32-36. [CrossRef]

29. Majeed, S.; Iqbal, M.; Asi, M.R.; Iqbal, S.Z. Aflatoxins and ochratoxin A contamination in rice, corn and corn products from Punjab, Pakistan. J. Cereal Sci. 2013, 58, 446-450. [CrossRef]

30. Alim, M.; Iqbal, S.Z.; Mahmood, Z.; Asi, M.R.; Zikar, H.; Chanda, H.; Malik, N. Survey of mycotoxins in retail market cereals, derived products and evaluation of their dietary intake. Food Control 2018, 84, 471-477. [CrossRef]

31. Sultana, N.; Tahira, I.; Kausar, M.; Hassan, S.M.; Hanif, N.Q. Dietary exposure and natural occurrence of total aflatoxins in basmati rice of pakistan. J. Food Prot. 2017, 80, 331-337. [CrossRef] [PubMed]

32. Ferre, F.S. Worldwide occurrence of mycotoxins in rice. Food Control 2016, 62, 291-298. [CrossRef]

33. Tanaka, K.; Sago, Y.; Zheng, Y.; Nakagawa, H.; Kushiro, M. Mycotoxins in rice. Int. J. Food Microbiol. 2007, 119, 59-66. [CrossRef] [PubMed]

34. Yazdanpanah, H.; Zarghi, A.; Shafaati, A.R.; Foroutan, S.M.; Aboul-Fathi, F.; Khoddam, A.; Nazari, F. Exposure assessment of the tehran population (Iran) to zearalenone mycotoxin. Iran. J. Pharm. Res. 2012, 11, 251-256. [PubMed]

35. Mitchell, N.J.; Chen, C.; Palumbo, J.D.; Bianchini, A.; Cappozzo, J.; Stratton, J.; Ryu, D.J.; Wu, F. A risk assessment of dietary Ochratoxin a in the United States. Food Chem. Toxicol. 2017, 100, 265-273. [CrossRef] [PubMed]

36. Golge, O.; Kabak, B. First report: Exposure estimates to ochratoxin A through wheat bread and rice intake in Turkey. J. Cereal Sci. 2016, 69, 213-217. [CrossRef]

37. Abdus-Salaam, R.B.; Atanda, O.O.; Sulyok, M.; Kimanya, M.E.; Krska, R.; Chilaka, C.A. Dietary Exposure to Mycotoxins and Risk Assessment for Adult Consumers of Locally Processed Rice from Nigeria. In Tropentag 2016: Solidarity in a Competing World Fair Use of Resources; Freyer, B., Tielkes, E., Eds.; Cuvillier Göttingen: Vienna, Austria, 2016.

38. Sirot, V.; Fremy, J.M.; Leblanc, J.C. Dietary exposure to mycotoxins and health risk assessment in the second French total diet study. Food Chem. Toxicol. 2013, 52, 1-11. [CrossRef] [PubMed]

39. Leblanc, J.C.; Tard, A.; Volatier, J.L.; Verger, P. Estimated dietary exposure to principal food mycotoxins from The First French Total Diet Study. Food Addit. Contam. 2005, 22, 652-672. [CrossRef] [PubMed]

40. Panrapee, I.; Phakpoom, K.; Thanapoom, M.; Nampeung, A.; Warapa, M. Exposure to aflatoxin B-1 in Thailand by consumption of brown and color rice. Mycotoxin Res. 2016, 32, 19-25. [CrossRef] [PubMed]

41. Park, J.; Kim, E.; Kim, Y. Estimation of the daily exposure of Koreans to aflatoxin $B_{1}$ through food consumption. Food Addit. Contam. 2004, 21, 70-75. [CrossRef] [PubMed]

42. Huong, B.T.; Tuyen, L.D.; Tuan, D.H.; Brimer, L.; Dalsgaard, A. Dietary exposure to aflatoxin B1, ochratoxin A and fuminisins of adults in Lao Cai province, Viet Nam: A total dietary study approach. Food Chem. Toxicol. 2016, 98, 127-133. [CrossRef] [PubMed]

43. Huong, B.T.M.; Tuyen, L.D.; Do, T.T.; Madsen, H.; Brimer, L.; Dalsgaard, A. Aflatoxins and fumonisins in rice and maize staple cereals in Northern Vietnam and dietary exposure in different ethnic groups. Food Control 2016, 70, 191-200. [CrossRef] 
44. Serrano, A.B.; Font, G.; Ruiz, M.J.; Ferrer, E. Co-occurrence and risk assessment of mycotoxins in food and diet from Mediterranean area. Food Chem. 2012, 135, 423-429. [CrossRef] [PubMed]

45. Shephard, G.S. Risk assessment of aflatoxins in food in Africa. Food Addit. Contam. Part A Chem. Anal. Control Expo. Risk Assess. 2008, 25, 1246-1256. [CrossRef] [PubMed]

46. Gonzalez, L.; Juan, C.; Soriano, J.M.; Molto, J.C.; Manes, J. Occurrence and daily intake of ochratoxin A of organic and non-organic rice and rice products. Int. J. Food Microbiol. 2006, 107, 223-227. [CrossRef] [PubMed]

47. Manizan, A.L.; Oplatowska-Stachowiak, M.; Piro-Metayer, I.; Campbell, K.; Koffi-Nevry, R.; Elliott, C.; Akaki, D.; Montet, D.; Brabet, C. Multi-mycotoxin determination in rice, maize and peanut products most consumed in côte d'ivoire by uhplc-ms/ms. Food Control 2017, 87, 22-30. [CrossRef]

48. Martins, C.; Assunção, R.; Cunha, S.C.; Fernandes, J.O.; Jager, A.; Petta, T.; Oliveira, C.A.; Alvito, P. Assessment of multiple mycotoxins in breakfast cereals available in the Portuguese market. Food Chem. 2018, 239, 132-140. [CrossRef] [PubMed]

49. European Community (EC). Commission Regulation No 401/2006 of 23 February 2006 Laying Down the Methods of Sampling and Analysis for the Official Control of the Levels of Mycotoxins in Foodstuffs; European Community: Brussels, Belgium, 2006.

50. Speijers, G.J.A.; Speijers, M.H.M. Combined toxic effects of mycotoxins. Toxicol. Lett. 2004, 153, 91-98. [CrossRef] [PubMed]

51. European Food Safety Authority (EFSA). Opinion of scientific panel on contaminants in food chain on request from the commission related to the potential increase of consumer health risk by a possible increase of the existing maximum levels for aflatoxins in almond, hazelnut, pistachios and derived products. EFSA J. 2007, 446, 1-127.

52. Groopman, J.D.; Kensler, T.W.; Wild, C.P. Protective interventions to prevent aflatoxin-induced carcinogenesis in developing countries. Annu. Rev. Public Health 2008, 29, 187-203. [CrossRef] [PubMed]

53. Ferlay, J.; Soerjomataram, I.; Dikshit, R.; Eser, S.; Mathers, C.; Rebelo, M.; Parkin, D.M.; Forman, D.; Bray, F. Cancer incidence and mortality worldwide: Sources, methods and major patterns in GLOBOCAN 2012. Int. J. Cancer 2015, 136, E359-E386. [CrossRef] [PubMed]

54. Ali, S.A.; Donahue, R.M.; Qureshi, H.; Vermund, S.H. Hepatitis B and hepatitis C in Pakistan: Prevalence and risk factors. Int. J. Infect. Dis. 2009, 3, 9-19. [CrossRef] [PubMed]

55. Abdulkadar, A.; Al-Ali, A.A.; Al-Kildi, A.M.; Al-Jedah, J.H. Mycotoxins in food products available in Qatar. Food Control 2004, 15, 543-548. [CrossRef]

56. Aydin, A.; Aksu, H.; Gunsen, U. Mycotoxin levels and incidence of mould in Turkish rice. Environ. Monit. Assess. 2011, 178, 271-280. [CrossRef] [PubMed]

57. Bansal, J.; Pantazopoulos, P.; Tam, J.; Cavlovic, P.; Kwong, K.; Turcotte, A.M.; Lau, B.P.; Scott, P.M. Surveys of rice sold in Canada for aflatoxins, ochratoxin A and fumonisins. Food Addit. Contam. Part A Chem. Anal. Control Expo. Risk Assess. 2011, 28, 767-774. [CrossRef] [PubMed]

58. Makun, H.A.; Dutton, M.F.; Njobeh, P.B.; Mwanza, M.; Kabiru, A.Y. Natural multi-occurrence of mycotoxins in rice from Niger State, Nigeria. Mycotoxin Res. 2011, 27, 97-104. [CrossRef] [PubMed]

59. Ok, H.E.; Kim, H.J.; Cho, T.Y.; Oh, K.S.; Chun, H.S. Determination of Deoxynivalenol in Cereal-Based Foods and Estimation of Dietary Exposure. J. Toxicol. Environ. Health A 2009, 72, 1424-1430. [CrossRef] [PubMed]

60. Abdullah, A.B.; Ito, S.; Adhana, K. Estimate of Rice Consumption in Asian Countries and the World Towards 2050. 2006. Available online: http:/ / worldfood.apionet.or.jp/alias (accessed on 6 May 2017).

61. Jalili, M.; Jinap, S.; Son, R. The effect of chemical treatment on reduction of aflatoxins and ochratoxin a in black and white pepper during washing. Food Addit. Contam. Part A Chem. Anal. Control Expo. Risk Assess. 2011, 28, 485-493. [CrossRef] [PubMed]

62. Hussain, A.; Luttfullah, G. Reduction of Aflatoxin-B $B_{1}$ and Ochratoxin-A levels in Polished Basmati Rice (Oryza sativa Linn.) by Different Cooking Methods. J. Chem. Soc. Pak. 2009, 31, 911-915.

63. Park, J.W.; Kim, Y.B. Effect of pressure cooking on aflatoxin $B_{1}$ in rice. J. Agric. Food Chem. 2006, 54, $2431-2435$. [CrossRef] [PubMed]

64. Park, J.W.; Lee, C.; Kim, Y.B. Fate of aflatoxin $B_{1}$ during the cooking of Korean polished rice. J. Food Prot. 2005, 68, 1431-1434. [CrossRef] [PubMed]

65. Sani, A.M.; Azizi, E.G.; Salehi, E.A.; Rahimi, K. Reduction of aflatoxin in rice by different cooking methods. Toxicol. Ind. Health 2014, 30, 546-550. [CrossRef] [PubMed] 
66. Andrade, P.D.; de Mello, M.H.; Franca, J.A.; Caldas, E.D. Aflatoxins in food products consumed in Brazil: A preliminary dietary risk assessment. Food Addit. Contam. Part A Chem. Anal. Control Expo. Risk Assess. 2013, 30, 127-136. [CrossRef] [PubMed]

67. Sakuma, H.; Watanabe, Y.; Furusawa, H.; Yoshinari, T.; Akashi, H.; Kawakami, H.; Saito, S.; Sugita-Konishi, Y. Estimated Dietary Exposure to Mycotoxins after Taking into Account the Cooking of Staple Foods in Japan. Toxins 2013, 5, 1032-1042. [CrossRef] [PubMed]

68. Raad, F.; Nasreddine, L.; Hilan, C.; Bartosik, M.; Parent-Massin, D. Dietary exposure to aflatoxins, ochratoxin A and deoxynivalenol from a total diet study in an adult urban Lebanese population. Food Chem. Toxicol. 2014, 73, 35-43. [CrossRef] [PubMed]

69. Ding, X.X.; Li, P.W.; Bai, Y.Z.; Zhou, H.Y. Aflatoxin $B_{1}$ in post-harvest peanuts and dietary risk in China. Food Control 2012, 23, 143-148. [CrossRef]

70. Li, R.; Wang, X.; Zhou, T.; Yang, D.X.; Wang, Q.; Zhou, Y. Occurrence of four mycotoxins in cereal and oil products in Yangtze Delta region of China and their food safety risks. Food Control 2014, 35, 117-122. [CrossRef]

71. Chin, C.K.; Abdullah, A.; Sugita-Konishi, Y. Dietary intake of aflatoxins in the adult Malaysian population-An assessment of risk. Food Addit. Contam. B Surveill. 2012, 5, 286-294. [CrossRef] [PubMed]

72. Sugita-Konishi, Y.; Sato, T.; Saito, S.; Nakajima, M.; Tabata, S.; Tanaka, T.; Norizuki, H.; Itoh, Y.; Kai, S.; Sugiyama, K.; et al. Exposure to aflatoxins in Japan: Risk assessment for aflatoxin $\mathrm{B}_{1}$. Food Addit. Contam. Part A Chem. Anal. Control Expo. Risk Assess. 2010, 27, 365-372. [CrossRef] [PubMed]

73. Umer, M.; Iqbal, M. Hepatitis $C$ virus prevalence and genotype distribution in Pakistan: A comprehensive review of recent data. World J. Gastroenterol. 2016, 22, 1684-1700. [CrossRef] [PubMed]

74. Climate Data Processing Centre. Pakistan Meterological Department. 2017. Available online: http://www. pmd.gov.pk/cdpc/home.htm (accessed on 5 June 2017).

75. Salma, S.; Rehman, S.; Shah, M. Rainfall trends in different climate zones of Pakistan. Pak. J. Meteorol. 2012, 9 , $37-47$.

76. Monbaliu, S.; Van Poucke, C.; Detavernier, C.; Dumoulin, F.; Van De Velde, M.; Schoeters, E.; Van Dyck, S.; Averkieva, O.; Van Peteghem, C.; De Saeger, S. Occurrence of Mycotoxins in Feed as Analyzed by a Multi-Mycotoxin LC-MS/MS Method. J. Agric. Food Chem. 2010, 58, 66-71. [CrossRef] [PubMed]

77. Monbaliu, S.; Van Poucke, C.; Van Peteghem, C.; Van Poucke, K.; Heungens, K.; De Saeger, S. Development of a multi-mycotoxin liquid chromatography/tandem mass spectrometry method for sweet pepper analysis. Rapid Commun. Mass Spectrom. 2009, 23, 3-11. [CrossRef] [PubMed]

78. Majeed, S.; Iqbal, M.; Iqbal, S.Z.; Jinap, S.; Asi, M.R. Analysis of nutritional traits and aflatoxin contamination in selected maize varieties from Pakistan. J. Food Prot. 2017, 80, 1993-1998. [CrossRef] [PubMed]

79. Vinci, R.M.; Jacxsens, L.; Van Loco, J.; Matsiko, E.; Lachat, C.; de Schaetzen, T.; Canfyn, M.; Van Overmeire, I.; Kolsteren, P.; De Meulenaer, B. Assessment of human exposure to benzene through foods from the Belgian market. Chemosphere 2012, 88, 1001-1007. [CrossRef] [PubMed]

80. European Food Safety Authority (EFSA). Management of left-censored data in dietary exposure assessment of chemical substances. EFSA J. 2010, 8, 1557.

(C) 2018 by the authors. Licensee MDPI, Basel, Switzerland. This article is an open access article distributed under the terms and conditions of the Creative Commons Attribution (CC BY) license (http://creativecommons.org/licenses/by/4.0/). 